\title{
Enhanced removal of copper(II) from acidic streams using functional resins: batch and column studies
}

\author{
Anna Wołowicz ${ }^{1, *}$ (1) and Zbigniew Hubicki ${ }^{1}$ \\ ${ }^{1}$ Department of Inorganic Chemistry, Faculty of Chemistry, Institute of Chemical Sciences, Maria Curie-Sklodowska University, \\ Maria Curie-Sklodowska Square 2, 20-031 Lublin, Poland
}

Received: 21 February 2020

Accepted: 13 June 2020

Published online:

29 June 2020

(C) The Author(s) 2020

\begin{abstract}
The adsorption behaviour of copper(II) ions in acidic streams using different polymeric adsorbents (Lewatit MonoPlus TP 220, Lewatit MonoPlus SR 7, Lewatit AF 5, Purolite A 830, Purolite S 984, Purolite A 400 TL, Dowex PSR 2, Dowex PSR 3) was studied, and the results were compared. The adsorbents were characterized by determination of the point of zero charge and the Fourier transform infrared spectroscopy method. The kinetic (effects of phases contact time) and equilibrium (effect of initial $\mathrm{Cu}$ (II) concentration) studies were also carried out. The effects of hydrochloric and nitric(V) acids on adsorption behaviour of $\mathrm{Cu}$ (II) were examined. The FTIR spectra after the $\mathrm{Cu}(\mathrm{II})$ adsorption were also obtained, and the mechanism of $\mathrm{Cu}(\mathrm{II})$ sorption was proposed. Of eight adsorbents, the best one was chosen and applied in further studies (column adsorption, column and batch desorption, reuse of adsorbent in cycles of sorption-desorption, selectivity in two-component solutions $\mathrm{Pd}(\mathrm{II})-\mathrm{Cu}(\mathrm{II})$ ). $\mathrm{Cu}$ (II) sorption efficiency was the highest using Lewatit MonoPlus TP 220. Its sorption is well described by the pseudo-second-order kinetic equation and the Langmuir isotherm model. Ion exchangers show also high affinity for noble metals, especially for gold(III): $\mathrm{Au}(\mathrm{III})>\mathrm{Pd}(\mathrm{II})>\mathrm{Pt}(\mathrm{IV})$ (the column test) from single- and two- or three-component solutions (the batch test).
\end{abstract}

Address correspondence to E-mail: anna.wolowicz@poczta.umcs.lublin.pl 


\section{GRAPHIC ABSTRACT}

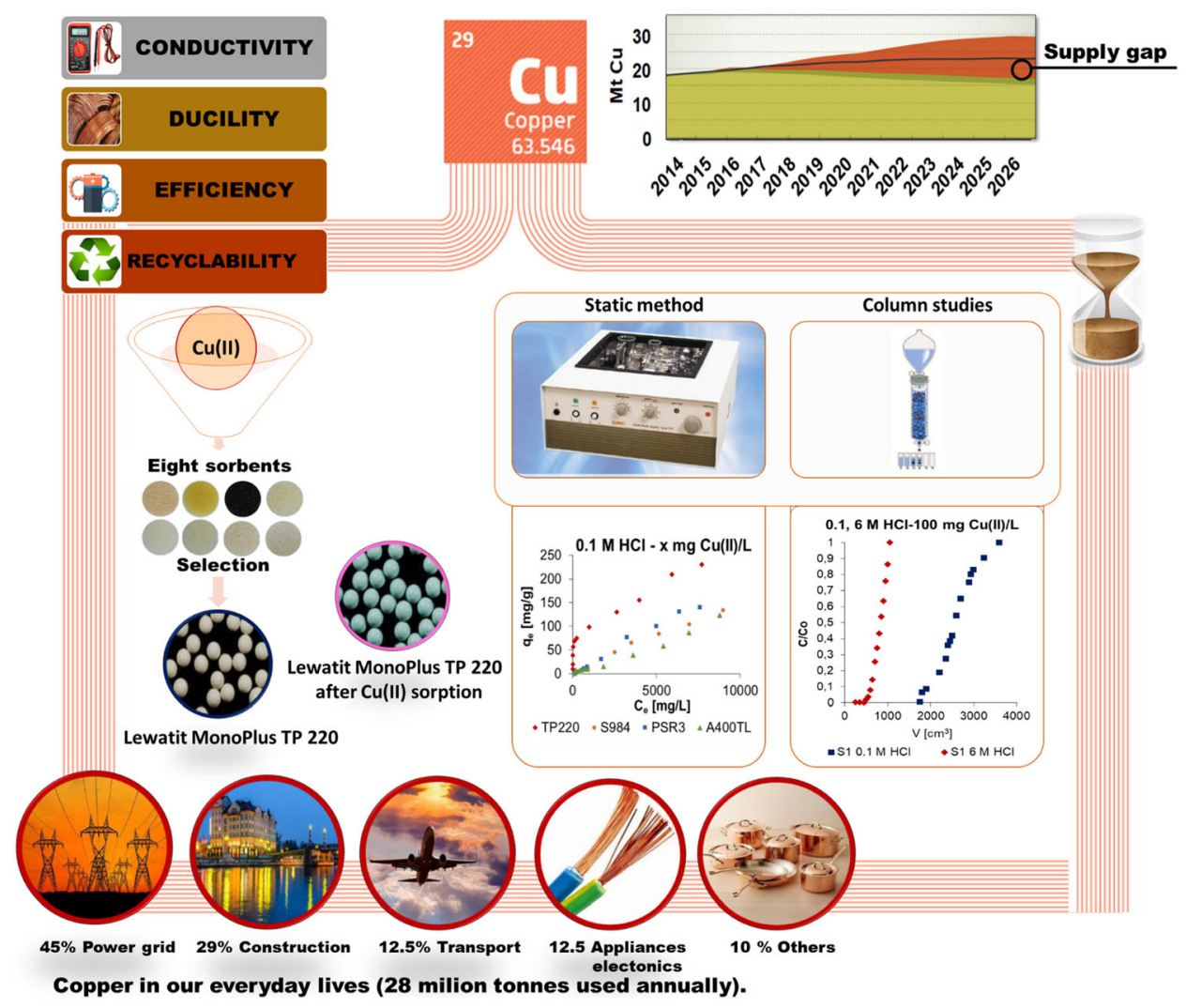

\section{Introduction}

Copper is metal of unique and beneficial properties (mechanical, physical and chemical ones), and it is highly valued in the world today [1]. Copper possesses excellent thermal and electrical conductivity, is ductile, in $100 \%$ recyclable and can be used many times without decreasing its quality. Moreover, copper can be combined with other metals forms alloys of much better properties than individual metals (about 570 of different copper alloys are known). Copper has a unique hue makes this metal also so attractive [1-3].

Copper found wide application in numerous branches of industry which is difficult to enumerate, among others such as: air-conditioning and refrigeration market, fish cages production, architecture, building construction market, art, coins, design and manufacture, electrical system, energy and renewables, agriculture and farming, healthcare, interior design, pipe systems, transportation, etc. [2-6]. 15\% of copper is consumed in industrial machinery, $5 \%$ in alloy production, $20 \%$ in plumbing and roofing and $60 \%$ in electrical wires production.

Due to numerous uses of copper, various wastewaters containing this metal are produced during the metallurgical treatment of copper concentrates, during copper refining, electrolyte regeneration steps and from sulphuric acid, zinc and noble metal plants, etc. Such wastewaters are characterized by high concentration of acids and they usually contain not only copper but also other heavy metal ions such as nickel, cobalt, zinc, lead, iron, etc. [7, 8]. Copper content in such wastewaters is usually lower than $1000 \mathrm{mg} / \mathrm{L}$, and according to the World Health 
Organization (WHO) the maximum acceptable concentration of $\mathrm{Cu}(\mathrm{II})$ in water is equal to $1.5 \mathrm{mg} / \mathrm{L}$ [9]; therefore, due to the high outflows of such wastewaters many valuable as well as toxic metals are potentially lost and discharged. One sustainable option to decrease potential environmental pollution as well as to reuse heavy metal ions is recovery of valuable metals from polymetallic acidic streams. Recycling of copper saves resources and also helps save energy. Many different methods have been studied for heavy metal ions removal from industrial waters and wastewaters [10-15]. These treatment methods can be divided into three categories such as chemical, physical as well as biological. Physicochemical treatment methods (Fig. S1) such as chemical precipitation (hydroxide, sulphide precipitation, combined methods, chelating precipitation), ion exchange, adsorption, bioadsorption, coagulation, flocculation, flotation, membrane filtration [ultrafiltration (UF), micellar-enhanced ultrafiltration (MEUF) and polymer enhanced ultrafiltration (PEUF), reverse osmosis (RO), nanofiltration (NF), electrodialysis (ED), polymer inclusion membranes (PIMs)] and electrochemical treatment are the most suitable for the removal of heavy metal ions as well as copper(II) ions from industrial wastewaters [10-16]. As can be seen from Table S1 all physicochemical methods possess advantages and limitations. Chemical precipitation is applied for heavy metal ions removal from wastewaters of their high concentration due to its simplicity and inexpensive capital cost, but this method is ineffective when heavy metal ions concentration is low. Moreover, this method is not economical and produced large amount of sludge. Ion exchange method has been widely applied for the removal of heavy metal ions, but ion exchange resins need regeneration after exhausting by chemical reagents and secondary pollution is produced. Method is not recommended for large scale due to its high capital cost when a large amount of wastewaters containing heavy metal ions of low concentration needs to be treated. On the other hand, coagulation and flocculation produce sludge of good sludge settling and dewatering, but due to high consumption of chemicals and production of sludge of big volume this method did not play the most significant role in heavy metal ions removal. The main advantage of membrane filtration is high efficiency for heavy metal ions removal, but its high cost, complexity of process, fouling of membrane and low permeate flux result in its limited application. High selectivity and metals removal efficiency, low operating cost, generation of more concentrated sludge, high overflow rates are the main advantages of flotation, but this method is characterized by high initial capital and maintenance costs. Electrochemical treatment method possesses drawbacks such as capital cost, high energy consumption, and despite less production of sludge compared to filtration and lower consumption of chemicals, this technology has restricted application for heavy metal ions removal [10-16]. Adsorption is a technique of well-established position for copper and other heavy metal ions removal [10-12,14]. It is one of the most economical methods and is characterized by many advantages compared to the other treatment techniques. Advantages of this method involve low investment cost, simplicity and flexibility in design and operation, produce high-quality treated effluent, wide range of commercially available adsorbents of good mechanical and kinetics properties, high efficiency and selectivity towards heavy metal ions of different concentrations. The efficiency of this method depends on the type of adsorbents, and due to the fact that adsorption could be reversible, the regeneration step is possible when the adsorbent is exhausted. On the other hand, the regeneration step could result in secondary pollutant production, but quantitative desorption ensures reuse of adsorbent results in cost reduction [10, 12].

Copper is an element essential for proper organisms growth and development. It takes part in oxidative-reduction processes, where it occurs as a coenzyme, regulates metabolism and transports oxygen for cells as well as stimulates the amount and activity of haemoglobin, etc. On the other hand, excess or deficiency of copper causes disorders manifested in various disease syndromes e.g. anaemia, growth and fertility restrictions, nervous system disorders, and cardiovascular diseases. Excess of this element may cause liver and kidney damage and even death. The most toxic is copper sulphate(VI) as well as copper oxides result in chronic poisoning. Copper compounds act on intact skin, causing inflammation, itching, ulceration of the mucosa, conjunctivitis, nasal septum and pharynx, etc. Additionally, negative effects of copper on humans and plants are shown in Fig. 1. Higher concentration of copper $\left(>100 \mu \mathrm{g} / \mathrm{dm}^{3}\right)$ inhibits the growth of green plants, whereas concentrations in the range from 80 

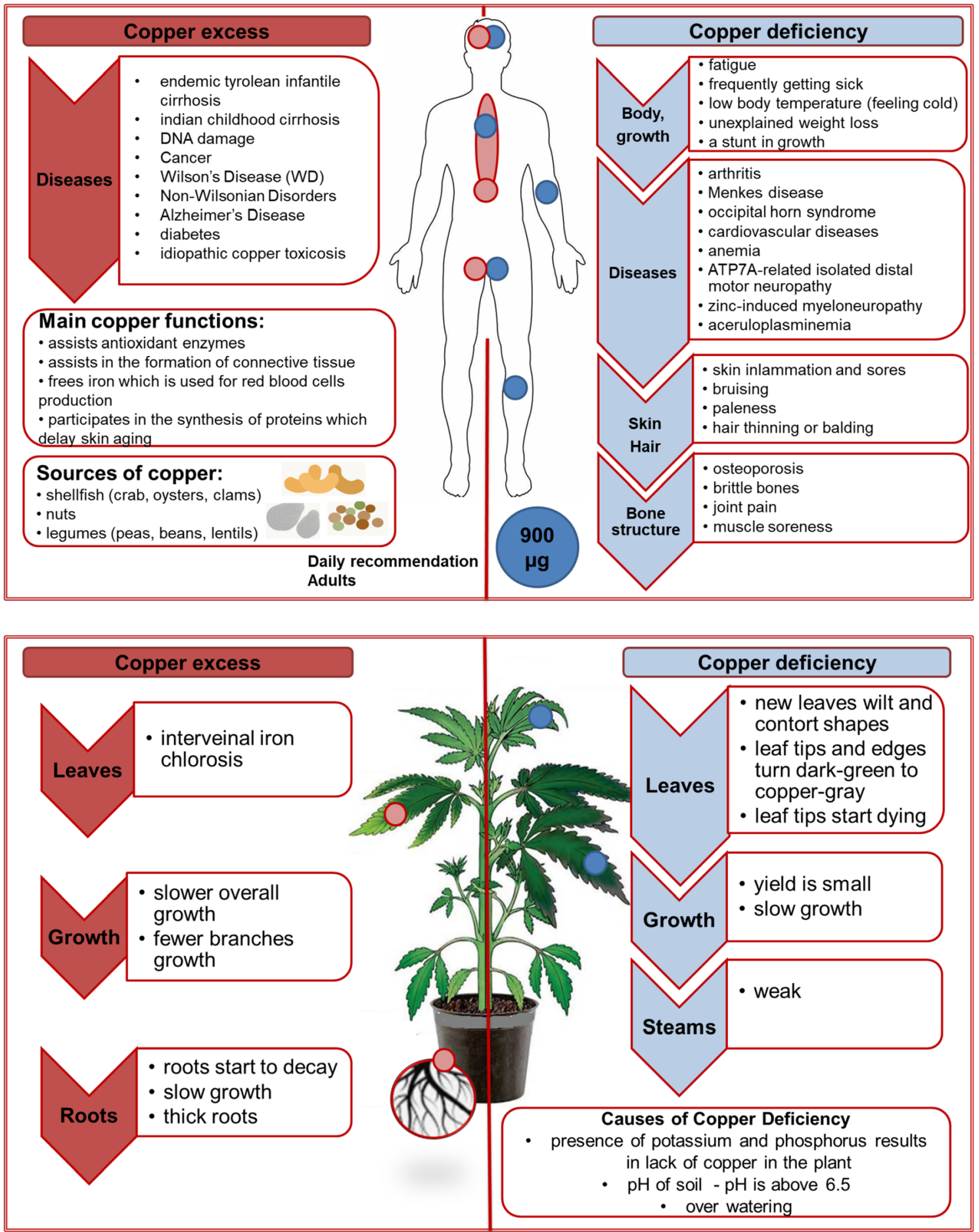

Figure 1 Effect of deficiency and excess of copper on human and plants.

to $800 \mu \mathrm{g} / \mathrm{dm}^{3}$ is very dangerous for fish. Selfcleaning processes is inhibited at concentrations of copper equal to $10 \mu \mathrm{g} / \mathrm{dm}^{3}$, and the bitter taste of water appears at copper concentration above
$1000 \mu \mathrm{g} / \mathrm{dm}^{3}$. Toxicity of cooper is higher in soft water of higher $\mathrm{pH}[4,17-20]$.

Based on the toxic, ecological and economical aspects, the aim of this paper was the study of copper(II) removal from acidic streams by different types 
of ion exchangers. Ion exchange method and adsorption overcome many drawbacks of other methods applied for polymetallic wastewaters treatment and are able to meet strict discharge requirements. In the present study, copper(II) removal from acidic streams by eight different types of ion exchangers was investigated. The effects of phases contact time and acids concentration on copper(II) efficiency removal were studied. Moreover, both $\mathrm{pH}_{\mathrm{PZC}}$ and isotherms were obtained for the ion exchangers under discussion. For the most efficient sorbent for copper(II) removal, additional studies were carried out. The kinetic and equilibrium studies were modelled using the pseudo-first (PFO), pseudosecond (PSO) kinetic order as well as the Langmuir and Freundlich models. Additionally, possibility of Lewatit MonoPlus TP 220 regeneration and reuse (3 cycles of sorption-desorption) were analysed using different eluting agents and the static method. For full characteristics of copper(II) removal by Lewatit MonoPlus TP 220, both the fixed bed adsorption and desorption as well as the ion exchange resin reuse by the column method were presented and compared with noble metals such as palladium(II), platinum(IV) and gold(III) removal efficiency. The attenuated total reflectance Fourier transform infrared spectroscopy (ATR-FTIR) spectra for Lewatit MonoPlus TP220 after copper(II) sorption and binary containing palladium(II) and copper(II) and tertiary components solutions containing noble metal ions were also discussed.

\section{Experimental}

\section{Sorbate and ion exchange resins characteristics}

Copper(II) working solutions of $100 \mathrm{mg} / \mathrm{L}$ concentration were prepared from the stock solutions $\left(10000 \mathrm{mg} / \mathrm{L}, \mathrm{CuCl}_{2} \cdot 2 \mathrm{H}_{2} \mathrm{O}\right.$ in $0.1 \mathrm{M} \mathrm{HCl}$ ) by dilution with $\mathrm{HCl}$ or $\mathrm{HCl}-\mathrm{HNO}_{3}$ addition to obtain different acid concentrations. The solutions possess the following composition: 0.1-6.0 M HCl-100 mg Cu(II)/ $\mathrm{L} ; 0.1-0.9 \mathrm{M} \mathrm{HCl}-0.9-0.1 \mathrm{M} \mathrm{HNO}_{3}-100 \mathrm{mg} \mathrm{Cu}(\mathrm{II}) / \mathrm{L}$. Other multicomponent solutions were prepared in a similar way using $\mathrm{PdCl}_{2}, \mathrm{H}_{2} \mathrm{PtCl}_{6}, \mathrm{HAuCl}_{4}$ compounds. Salts, acids, bases of analytical grade used in the studies were purchased from POCH S.A. Gliwice.
The composition $\left(\mathrm{HCl}, \mathrm{HCl}-\mathrm{HNO}_{3}\right)$ and concentration of heavy metal ions were selected in such a way that they reflect real solutions derived from hydrometallurgical leaching of waste materials containing precious metals and basic ones, e.g. copper ions. Noble and base metals from waste materials such as anodic slimes or spent automobile catalyst can be separated by pyrometallurgical or hydrometallurgical as well as mixed processes. Waste materials (catalyst) are treated (leaching process) using a suitable agent or a mixture of agents. These metals can be brought to the solutions using, e.g. mixture of nitric $(\mathrm{V})$ acid, sulphuric(VI) acid or hydrochloric acid $\left(\mathrm{HCl}, \mathrm{HNO}_{3}\right.$ and $\left.\mathrm{H}_{2} \mathrm{SO}_{4}\right)$, aqua regia $\left(\mathrm{HCl}-\mathrm{HNO}_{3}\right)$, mixture of hydrochloric acid and chlorine $\left(\mathrm{HCl}-\mathrm{Cl}_{2}\right)$ or mixture of hydrochloric acid and sodium chloride ( $\mathrm{HCl}-\mathrm{NaCl})$, etc. [21-23]. Hydrometallurgical methods are also employed to enrich noble metals and to recover base metals from anodic slimes. Most of the base metals, e.g. copper, is treated by acids like sulphuric(VI) acid, $4 \mathrm{M}$ nitric(V) acid, $4 \mathrm{M}$ hydrochloric acid, etc. [24, 25].

The ion exchanger under discussion was selected from commercially available resins supplied by resin manufacturing companies. After their pre-preparation according to the standard procedure [26], they were applied for copper(II) removal from acidic solutions. These functional resins belong to different types such as chelating, anionic ion exchangers or sorbent without functional groups. They are polyacrylic, styrene-divinylbenzene or carbonaceous functional resins with micro- or macroporous structure. The more detailed characteristics of functional resins (based on their product data sheets) are presented in Fig. 2. Ion exchangers were selected on the basis of their availability, price, physicochemical properties, type of functional groups as well as due to the type and composition of the solutions tested. Metals occur in solutions under discussion usually in the form of metal-chlorocomplexes or mixed complexes; therefore, the application of weakly and strongly basic and chelating resins is a promising way to recovered them. In addition, new generation of ion exchangers were applied here whose sorption properties towards copper and precious metal ions have not been discussed in the literature. 

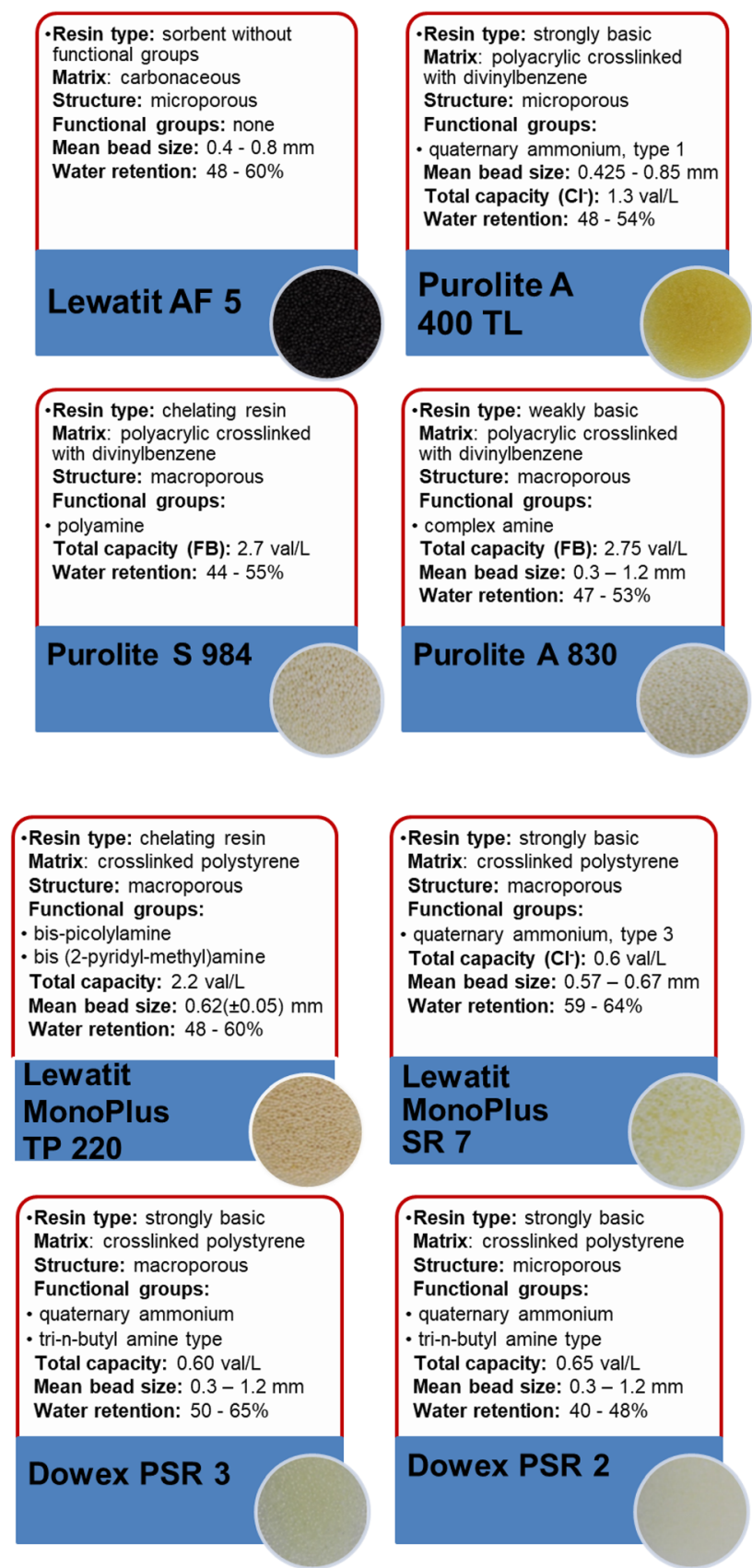

Resin type: strongly basic Matrix: crosslinked polystyrene Structure: microporous Functional groups:

- quaternary ammonium

- tri-n-butyl amine type

Total capacity: $0.65 \mathrm{val} / \mathrm{L}$

Mean bead size: $0.3-1.2 \mathrm{~mm}$

Water retention: $40-48 \%$

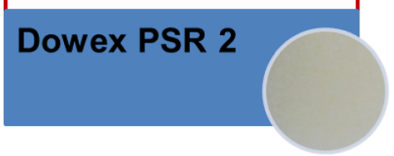

Figure 2 Characteristics of functional resins used in copper(II) removal from acidic streams.

\section{Sorption studies by the batch test}

The batch test was applied in copper(II) removal from acidic solutions on the functional resins such as Lewatit MonoPlus TP 220, Lewatit MonoPlus SR 7, Lewatit AF 5, Purolite A 830, Purolite S 984, Purolite A 400 TL, Dowex PSR 2, Dowex PSR 3 and amount of copper(II) sorbed at time $t\left(q_{\mathrm{t}}, \mathrm{mg} / \mathrm{g}\right)$, sorption capacities $\left(q_{\mathrm{e}}, \mathrm{mg} / \mathrm{g}\right)$ and percentage removal efficiency $(\% R)$ were determined. Not only efficiency of copper(II) ions removal but also rate of its removal is a very important factor; therefore, the effects of phases contact time on copper(II) removal were also investigated. The procedure of the batch test is as follows: (1) sorbate and sorbent phases preparation, (2) both phases contacted in the $100 \mathrm{~mL}$ Erlenmeyer flask at room temperature by shaking $0.5( \pm 0.0005) \mathrm{g}$ of functional resin with $0.05 \mathrm{~L}$ of $100 \mathrm{mg} \mathrm{Cu}(\mathrm{II}) / \mathrm{L}$ solutions (shaking parameters: amplitude 8, agitation speed 180 stock/min, shaking time was in the range 1-240 min, the mechanical shaker Elphin +, type 357, Lubawa, Poland), (3) phases separation by filtration (filter paper), (4) determination of copper concentration in solution after the sorption process by the atomic absorption spectrometry method (AAS) (spectrometer Varian AA240FS, Australia) using copper standard solutions and calibration curve, (5) amount of copper(II) sorbed at time $t\left(q_{\mathrm{t}}, \mathrm{mg} / \mathrm{g}\right)$ and sorption capacity, amount of copper(II) ions sorbed at equilibrium time $\left(q_{\mathrm{e}}, \mathrm{mg} / \mathrm{g}\right)$ as well as percentage efficiency removal $(\% R)$ calculation using the following equations:

- Amount of copper(II) ions sorbed at time $t\left(q_{\mathrm{t}}\right.$, $\mathrm{mg} / \mathrm{g})$ :

$q_{\mathrm{t}}=\left(C_{0}-C_{\mathrm{t}}\right) V / m_{j}$

- Amount of copper(II) ions sorption at equilibrium time, sorption capacity $\left(q_{\mathrm{e}}, \mathrm{mg} / \mathrm{g}\right)$ :

$q_{\mathrm{e}}=\left(C_{0}-C_{\mathrm{e}}\right) V / m_{j}$

where $C_{\mathrm{o}}$ is the initial concentration of copper(II) ions before the sorption process, $C_{\mathrm{e}}$ is the copper(II) ions concentration at equilibrium $(\mathrm{mg} / \mathrm{L})$, $V$ is the volume of solution $(0.05 \mathrm{~L}), m_{j}$ is the mass of functional resin $(\mathrm{g})$ [27],

- Percentage removal efficiency of copper(II), $(R$, $\%)$ :

$$
R=\frac{\left(C_{0}-C_{\mathrm{e}}\right)}{C_{0}} \times 100 \%
$$

where $C_{\mathrm{o}}$ is the initial copper(II) ions concentration $(\mathrm{mg} / \mathrm{L})$ and $C_{\mathrm{e}}$ is the equilibrium copper(II) ions concentration $(\mathrm{mg} / \mathrm{L})$ [28].

The $\mathrm{Cu}(\mathrm{II})$ adsorption on examined sorbents was performed in triplicate, and the arithmetic mean values were obtained and presented in figures. The 
calculated standard deviation did not exceed 5\% in all cases.

The point of zero charge $\left(\mathrm{pH}_{\mathrm{PZC}}\right)$ of sorbents under discussion was performed according to the solid addition method using the following parameters (mass of sorbent- $0.5 \mathrm{~g}$; volume of the solution of different $\mathrm{pH}-50 \mathrm{~mL}$; agitation speed-180 spm; time of shaking-24 h) [29].

Equilibrium studies were carried out using the above described static procedure. The initial copper(II) concentration was in the range 100-10000 mg/ $\mathrm{L}$, and the shaking time was equal to $24 \mathrm{~h}$.

Desorption efficiency using different eluting agents and reuse studies (three sorption -desorption cycles) for the most efficient sorbent was determined.

The removal efficiency of copper(II) using ion exchangers under discussion was also analysed in the two-component solutions $\mathrm{Pd}(\mathrm{II})-\mathrm{Cu}(\mathrm{II})$. Moreover, removal efficiency of noble metals $\mathrm{Pd}(\mathrm{II}), \mathrm{Pt}(\mathrm{IV})$ and $\mathrm{Au}(\mathrm{III})$ from tertiary components solutions on Lewatit MonoPlus TP 220 was also discussed.

\section{Sorption studies by the column test}

Metal ions removal by the batch method was used for preliminary screening of the systems resulting in maximum uptake, effectiveness of sorbents determination, but the practical utility of a sorbent is judged from the column operation. Therefore, $\mathrm{Cu}$ (II) removal by the column studies was carried out. In the dynamic studies, Lewatit MonoPlus TP $220\left(10 \mathrm{~cm}^{3}\right.$ of swollen ion exchanger) was placed in the glass column of $1 \mathrm{~cm}$ diameter and $25 \mathrm{~cm}$ high and contacted continuously with fresh solutions of the initial solute concentration of $100 \mathrm{mg} / \mathrm{L}$ (flow rate was $0.4 \mathrm{~cm}^{3} / \mathrm{min}$ ). The efficiency of column could be judged by means of the breakthrough curve obtained by plotting $C / C_{0}$ (ratio of effluent concentration to the initial concentration of solution) versus the volume of the effluent collected from the column. The volumes of the effluents to reach the breakthrough point and shape of the breakthrough curve are very important characteristics for determining the working ion exchange capacity $\left(C_{\mathrm{w}}\right)$, mass $\left(D_{\mathrm{m}}\right)$ and bed $\left(D_{\mathrm{b}}\right)$ distribution coefficients. These parameters were calculated based on Eqs. 4-6 presented in Table 1 and compared to the others obtained for noble metal ions.

\section{Results and discussion}

\section{The point of zero charge determination of the resins under discussion}

The point of zero charge $\left(\mathrm{pH}_{\mathrm{PZC}}\right)$ of the sorbents under discussion was determined using the solid addition method [29]. The solutions of $0.01 \mathrm{M} \mathrm{KNO}_{3}$ of different $\mathrm{pH}$ values were prepared applying $1 \mathrm{M}$ $\mathrm{NaOH}$ and $1 \mathrm{M} \mathrm{HCl}$ solutions to adjusted $\mathrm{pH}$, and then $50 \mathrm{ml}$ of solutions was contacted with $0.5 \pm 0.0005 \mathrm{~g}$ of sorbent for $24 \mathrm{~h}$. After that, the $\mathrm{pH}$ was measured again (final $\mathrm{pH}, \mathrm{pH}_{\mathrm{f}}$ ) using the $\mathrm{pH}$ meter CP-411 (Elmetron, Zabrze) and the plot $\mathrm{pH}_{\mathrm{o}}$ (initial $\mathrm{pH}$ of the solutions) versus the difference between the initial $\left(\mathrm{pH}_{\mathrm{o}}\right)$ and the final $\left(\mathrm{pH}_{\mathrm{f}}\right)$ ones was obtained. $\mathrm{pH}$ is a very important factor in metal ions sorption because it influences on chemical speciation of the metal ions in solution and, on the other hand, on the ionization of active sites on the sorbent. Sorbent surface charge might play a crucial role in sorption processes efficiency, and sorbents functionality (protonation-deprotonation behaviour) in aqueous acidic media could be helpful in sorption mechanism explanation [30]. Point of zero charge $\left(\mathrm{pH}_{\mathrm{PZC}}\right)$ is the $\mathrm{pH}$ at which the sorbent surface charge is neutral that means that there are equal amounts of
Table 1 Column parameters obtained for metal ions sorption on Lewatit MonoPlus TP 220

\begin{tabular}{llll}
\hline Parameters & Symbol & Equation & \\
\hline Working ion exchange capacity & $C_{\mathrm{w}}\left(\mathrm{g} / \mathrm{cm}^{3}\right)$ & $C_{\mathrm{w}}=\left(V_{\mathrm{p}} \cdot C_{\mathrm{o}}\right) / V_{\mathrm{j}}$ & (4) \\
Mass distribution coefficient & $D_{\mathrm{m}}$ & $D_{\mathrm{m}}=\left(U-U_{\mathrm{o}}-V_{\mathrm{v}}\right) / m_{\mathrm{j}}$ & $(5)$ \\
Bed distribution coefficient & $D_{\mathrm{v}}$ & $D_{\mathrm{v}}=D_{\mathrm{m}} d_{\mathrm{z}}$ & $(6)$ \\
\hline
\end{tabular}

$C_{\mathrm{o}}$ - initial concentration of metal ions $\left(\mathrm{mg} / \mathrm{dm}^{3}\right) ; V_{\mathrm{p}}$-volume of effluent collected to the breakthrough point $\left(\mathrm{cm}^{3}\right), V_{\mathrm{j}}$-volume of ion exchanger bed put into the columns $\left(10 \mathrm{~cm}^{3}\right), U-$ effluent volume at $C=0.5 C / C_{\mathrm{o}}\left(\mathrm{cm}^{3}\right), U_{\mathrm{o}}$ - dead volume in the column $\left(2 \mathrm{~cm}^{3}\right), V_{\mathrm{v}}$ - void (interparticle) ion exchanger bed volume (which amounts to ca. $0.4-4 \mathrm{~cm}^{3}$ ), $m_{j}$-dry ion exchanger weight $(\mathrm{g}), d_{\mathrm{z}}$ - the ion exchanger bed density 
Table 2 Point of zero charge of sorbents applied for $\mathrm{Cu}(\mathrm{II})$ removal from acidic solutions

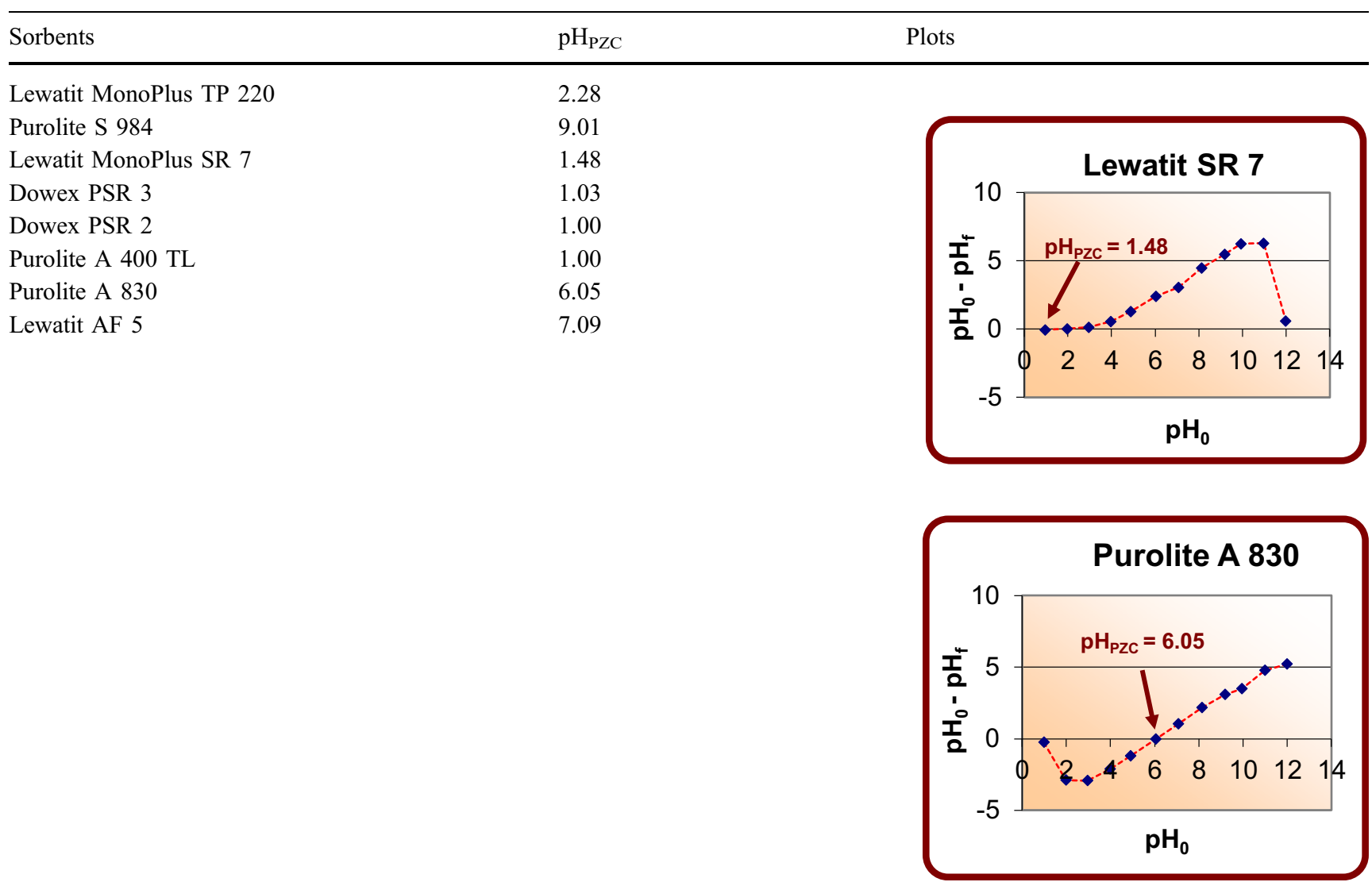

positive and negative surface sites. These values were determined from the above-mentioned plot: $\mathrm{pH}_{0}$ versus $\Delta \mathrm{pH}=\mathrm{pH}_{0}-\mathrm{pH}_{\mathrm{f}}$ in the place where such curves cross the $\mathrm{x}$ axis. Table 2 collects the values of $\mathrm{pH}_{\mathrm{PZC}}$ of the sorbents under discussion and presents chosen examples of experimentally obtained plots. In the case of the SBA resin, the $\mathrm{pH}_{\text {PZC }}$ is close to 1-1.5, whereas for the WBA and adsorbent without functional groups this value is higher.

As it was known, copper(II) interaction with the sorbents under discussion depends on the form in which metal exists as well as on the surface charge. In the acidic solutions $0.1-6 \mathrm{M} \mathrm{HCl}, \mathrm{Cu}(\mathrm{II})$ exists in the cation form $\mathrm{Cu}^{2+}$ as well as in the form of chlorocomplexes of different charges. The copper(II) species in the $\mathrm{HCl}$ system was previously described in [31]. At the solution $\mathrm{pH}$ higher than $\mathrm{pH}_{\mathrm{PZC}}$, the negatively charged sorbent surface results in possible interactions with copper positive species (electrostatic interactions), while at $\mathrm{pH}$ lower than $\mathrm{pH}_{\mathrm{PZC}}$ the positively charged surface results in electrostatic interactions with anionic copper species and repulsions with copper cations.

\section{Selection of the best ion exchangers for copper(II) removal}

Effects of phases contact time ( 1 min- $4 \mathrm{~h}$ ) as well as acids $\left(\mathrm{HCl}\right.$ and $\mathrm{HCl}-\mathrm{HNO}_{3}$ ) concentration and solutions composition on copper(II) removal efficiency using eight ion exchangers under discussion were studied previously [31-34] and in this paper according to the procedure described in Subchapter "Sorption studies by the batch test". The results of adsorption from the solutions of the initial concentration equal to $100 \mathrm{mg} \mathrm{Cu}(\mathrm{II}) / \mathrm{L}$ are presented in Fig. 3. Figure 3a-d presents the amount of copper(II) sorbed versus the phases contact time depending of the $\mathrm{HCl}$ concentration $(0.1-6.0 \mathrm{M} \mathrm{HCl})$. Due to the fact that the copper(II) removal efficiency was much lower from the $\mathrm{HCl}-\mathrm{HNO}_{3}$ systems, only chosen results are presented for this system. Figure 3e shows 

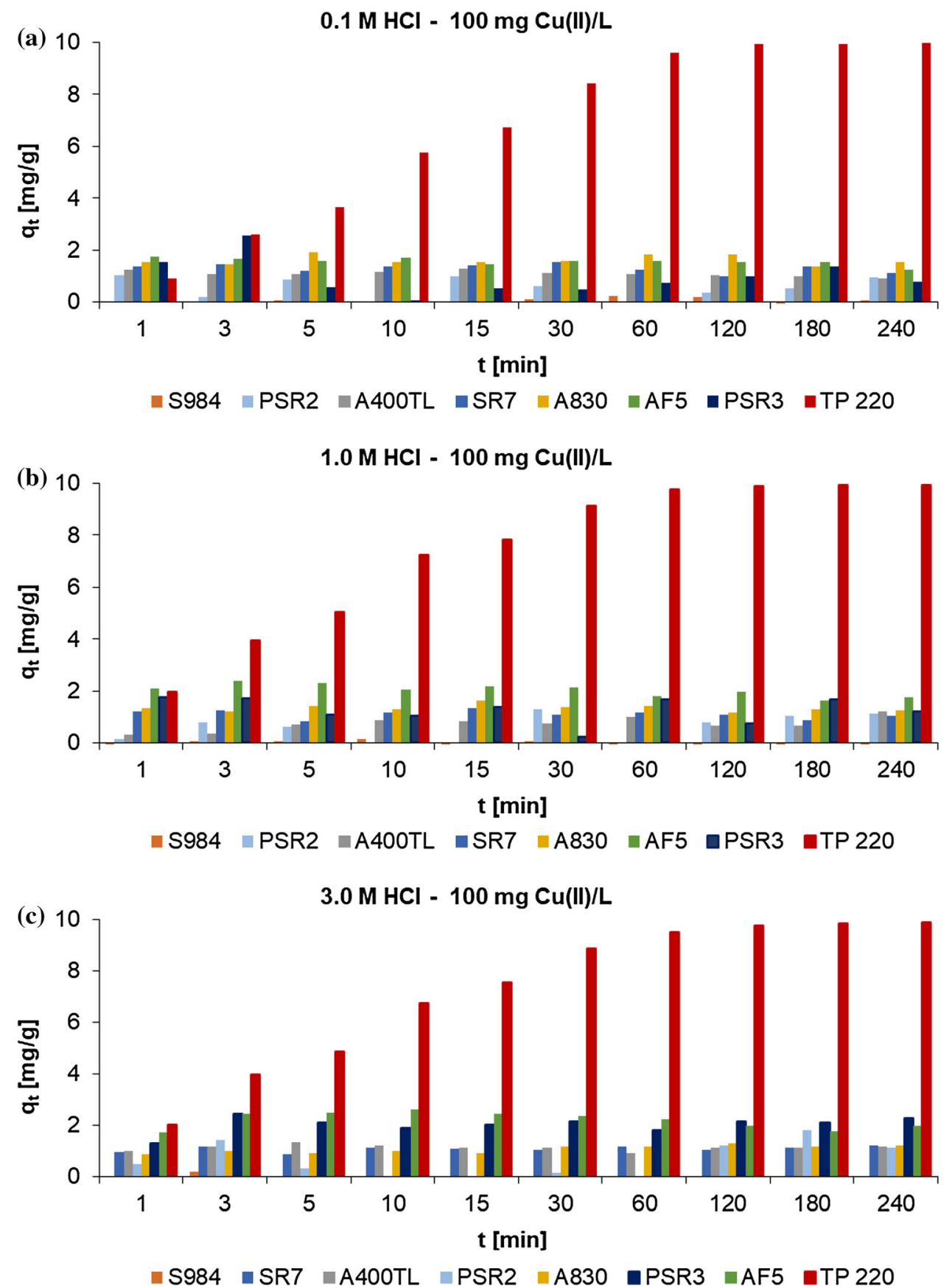

Figure 3 Comparison of the amount of copper(II) sorbed from a-d $\mathrm{HCl}$ and $\mathbf{e}-\mathbf{f} \mathbf{H C l}-\mathrm{HNO}_{3}$ systems (chosen example) (experimental conditions: mass of the ion exchanger: $m_{j}=0.5 \pm 0.0005 \mathrm{~g}$, volume of the $\mathrm{Cu}$ (II) solution: $V=0.05 \mathrm{~L}$, initial $\mathrm{Cu}$ (II) concentration: $C_{\mathrm{o}}=100 \mathrm{mg} / \mathrm{L}$, shaking rate: $V_{\mathrm{as}}=180 \mathrm{spm}$, amplitude: $A=8$, temperature: $T$ = ambient, shaking time: $t=1 \mathrm{~min}-4 \mathrm{~h}$ ).

the results obtained during copper(II) removal from $0.9 \mathrm{M} \mathrm{HCl}-0.1 \mathrm{M} \mathrm{HNO}_{3}$ solutions in which the $q_{\mathrm{t}}$ and $q_{\mathrm{e}}$ values were the highest, whereas Fig. 3f presents the results obtained from the $\mathrm{HCl}-\mathrm{HNO}_{3}$ system for Lewatit MonoPlus TP 220.

The obtained results lead to the following conclusions:
- Lewatit MonoPlus TP 220 shows the highest affinity for $\mathrm{Cu}$ (II) ions compared to the other ion exchangers under discussion in all examined $\mathrm{HCl}$ and $\mathrm{HCl}-\mathrm{HNO}_{3}$ systems.

- The highest sorption capacity in the dilute acid solutions as well as quantitative $\mathrm{Cu}$ (II) removal 

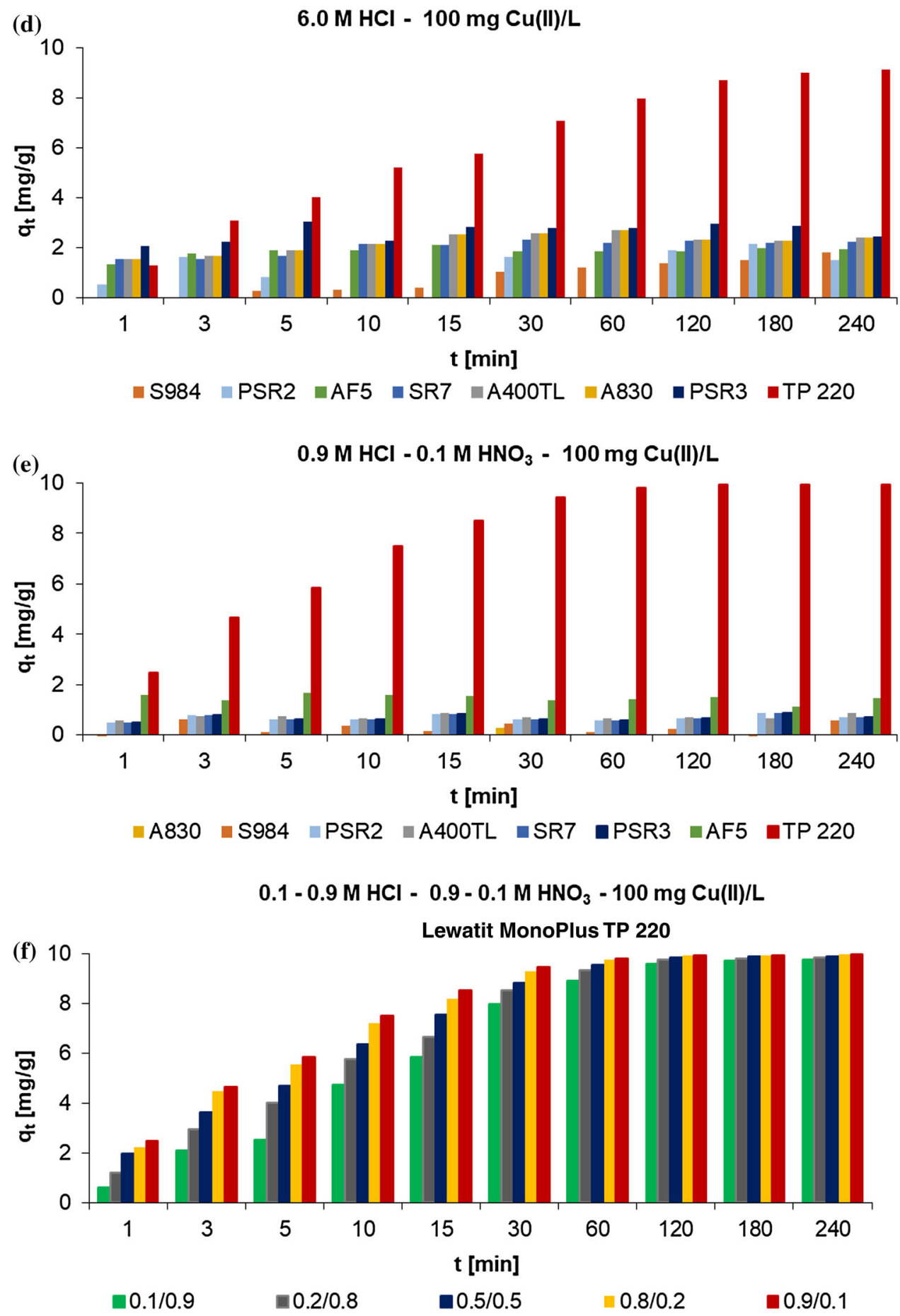

Figure 3 continued.

was obtained for the Lewatit MonoPlus TP 220 ion exchanger from $0.1,1.0 \mathrm{M} \mathrm{HCl}$ as well as from $0.9 \mathrm{M} \mathrm{HCl}-0.1 \mathrm{M} \mathrm{HNO}_{3}$ solutions. In this case, the $\% R$ is equal to $100 \%$, whereas for other acid concentrations the $\% R$ is close or slightly lower than $100 \%$ (91-99\%). Sorption is not quantitative in the case of other ion exchangers (Dowex PSR 2, Dowex PSR 3, Lewatit MonoPlus SR 7, Purolite A 400 TL, Lewatit AF 5, Purolite S 984, Purolit A 


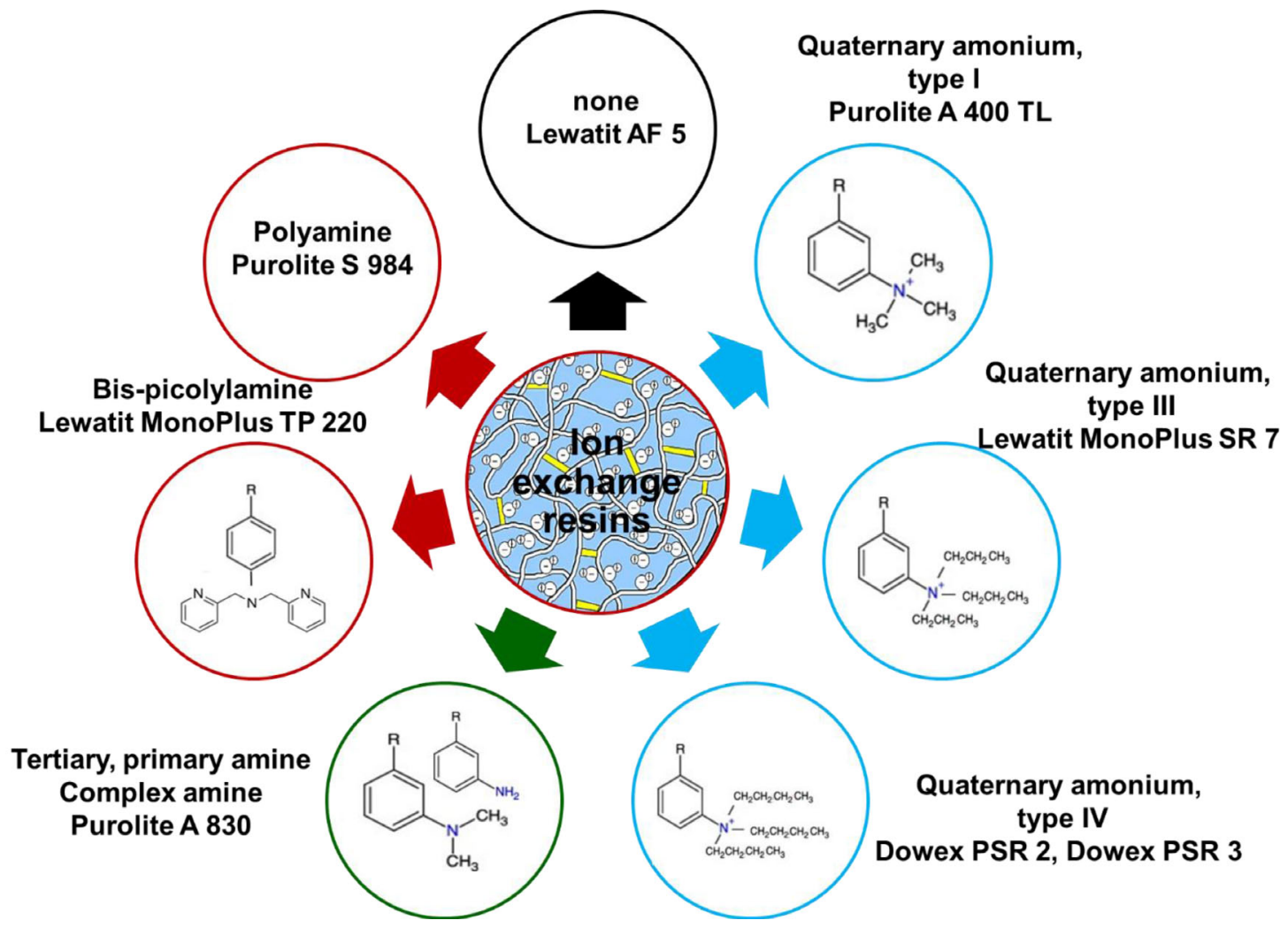

Strongly basic anion exchange resin, SBA

Weakly basic anion exchange resin, WBA

Chelating ion exchange resin

Sorbent without functional groups

Figure 4 Functional groups of ion exchange resins under discussion.

830). For these ion exchangers, $\% R$ is in the range from 0 to $35 \%$ ( $\mathrm{HCl}$ systems) and from 0 to $15 \%$.

- The effect of phases contact time on the amount of sorbed $\mathrm{Cu}(\mathrm{II})$ ions is clearly marked in the case of Lewatit MonoPlus TP 220 in the $\mathrm{HCl}$ and $\mathrm{HCl}-$ $\mathrm{HNO}_{3}$ systems as well as to a lesser extent for Purolite A 830 and Purolite S 984 in the systems of $6 \mathrm{M}$ hydrochloric acid concentration. The time required to achieve the system equilibrium for Lewatit MonoPlus TP 220 was $>120 \mathrm{~min}(\mathrm{HCl}$ systems) and $>60 \mathrm{~min}\left(\mathrm{HCl}-\mathrm{HNO}_{3}\right.$ systems). For the other ion exchangers under discussion, the $\mathrm{Cu}(\mathrm{II})$ sorption was not strongly time dependent; therefore, in contrast to Lewatit MonoPlus TP 220 the $q_{\mathrm{t}}$ values do not significantly increase with the phases contact time increase.
The $\mathrm{Cu}(\mathrm{II})$ sorption efficiency depends mainly on the ion exchange resin types, presence and types of functional groups, physical and chemical properties of the ion exchange resin as well as bead size [35]. Diversifying copper(II) ions removal effectiveness using the ion exchangers under discussion from acidic streams is caused by several factors: (1) ion exchangers possess a different matrix-usually they are polystyrene, polyacrylic cross-linked with divinylbenzene or carbonaceous matrices (Fig. 2), (2) the ion exchangers structure is macroporous or microporous, (3) ion exchangers possess different functional groups (Fig. 4), (4) the sorption uptake of $\mathrm{Cu}$ (II) ions depends on the acidic conditions which affect the ion exchangers functionality, (5) different mechanisms of $\mathrm{Cu}(\mathrm{II})$ sorption could proceed. 
Moreover, the difference in copper(II) removal in solutions of different acids concentrations could be caused by competition of the chloride ions with the $\mathrm{Cu}$ (II) ions. The behaviour of the anion exchange resins: weakly (WBA) and strongly basic (SBA) types in the $\mathrm{HCl}$ system are $\mathrm{pH}$ and total chloride ions concentration dependent as well as depend on the form in which $\mathrm{Cu}(\mathrm{II})$ ions exist under acidic conditions. The SBA resins are ionized in a wide $\mathrm{pH}$ range from 0 to 13, whereas the WBA ones are efficient in the acidic $\mathrm{pH}$ region in which the WBA functional groups are protonated which results in anions removal [31-33]. Ion exchangers of chelating types show higher selectivity towards the $\mathrm{Cu}$ (II) metal ions and can remove $\mathrm{Cu}$ (II) ions more effectively by means of a mixed mechanism. In this case combination of ionic interactions, electrostatic interactions and coordination could take place. Chelating ion exchange resins of the functional groups containing one, two or more donor atoms, e.g. N, S, O, can interact with the Lewis acids therefore such as Lewis bases; they can form coordinating bonds with the Lewis acids such as the $\mathrm{Cu}$ (II) ions, which results in extremely high selectivity for $\mathrm{Cu}$ (II) [31, 35-38]. Lewatit MonoPlus TP 220 as the ion exchange resin possesses three nitrogen donor atoms (two of them are in the aromatic pyridyl groups and tertiary amine) [39]. Electron-withdrawing effects of the aromatic group cause that $\mathrm{pKa}$ (negative logarithm of the acid dissociation constant) values are quite low, resulting in nitrogen atoms deprotonation even at $\mathrm{pH}$ of 1.5. The bis-picolylamine functional groups $\mathrm{pKa}$ values and those in the $\mathrm{HCl}$ system indicate that the behaviour of these functional groups depends on $\mathrm{pH}$ and the chloride ions [7, 31, 38, 39]. Large copper(II) removal is caused by the following factors: (1) at acidic $\mathrm{pH}$ two pyridyl nitrogen donor atoms are available and therefore the bidentate complex with $\mathrm{Cu}$ (II) can be formed, (2) $\mathrm{Cu}$ (II) possesses greater affinity compared to other transition metals (first stability constants for $\mathrm{Cu}(\mathrm{II})$ is equal to $\log K_{\mathrm{s}}=14.4$, whereas for $\mathrm{Ni}(\mathrm{II})$ $\log K_{\mathrm{s}}=8.7, \mathrm{Zn}(\mathrm{II})-\log K_{\mathrm{s}}=7.57$ etc. [40]), (3) Lewis acid-base interactions of bis-picolylamine and $\mathrm{Cu}$ (II) without electrostatic interactions take place. As reported in the literature and was proved in this paper, the chelating resins with bis-picolylamine are efficient for $\mathrm{Cu}$ (II) removal from acidic solutions $[31,35,39]$; therefore, such ion exchange resin was chosen in the additional studies.

\section{Equilibrium studies}

The selection of ion exchangers was also made on the basis of the equilibrium studies which allow to determine the maximum sorption capacities for copper(II) ions. The static procedure described in the Experimental part was applied, and the initial concentration of copper(II) solutions was in the range from 100 to $10000 \mathrm{mg} / \mathrm{L}$. Due to the fact that in this case the concentration of copper(II) ions was much higher than $100 \mathrm{mg} / \mathrm{L}$, the phases contact time extended to $24 \mathrm{~h}$ to be sure that the system equilibrium was achieved. The curves $q_{\mathrm{e}}(\mathrm{mg} / \mathrm{g})$ versus $C_{\mathrm{e}}$ $(\mathrm{mg} / \mathrm{L})$ are presented in Fig. 5 (different axis scales were applied for the results to be better observed).
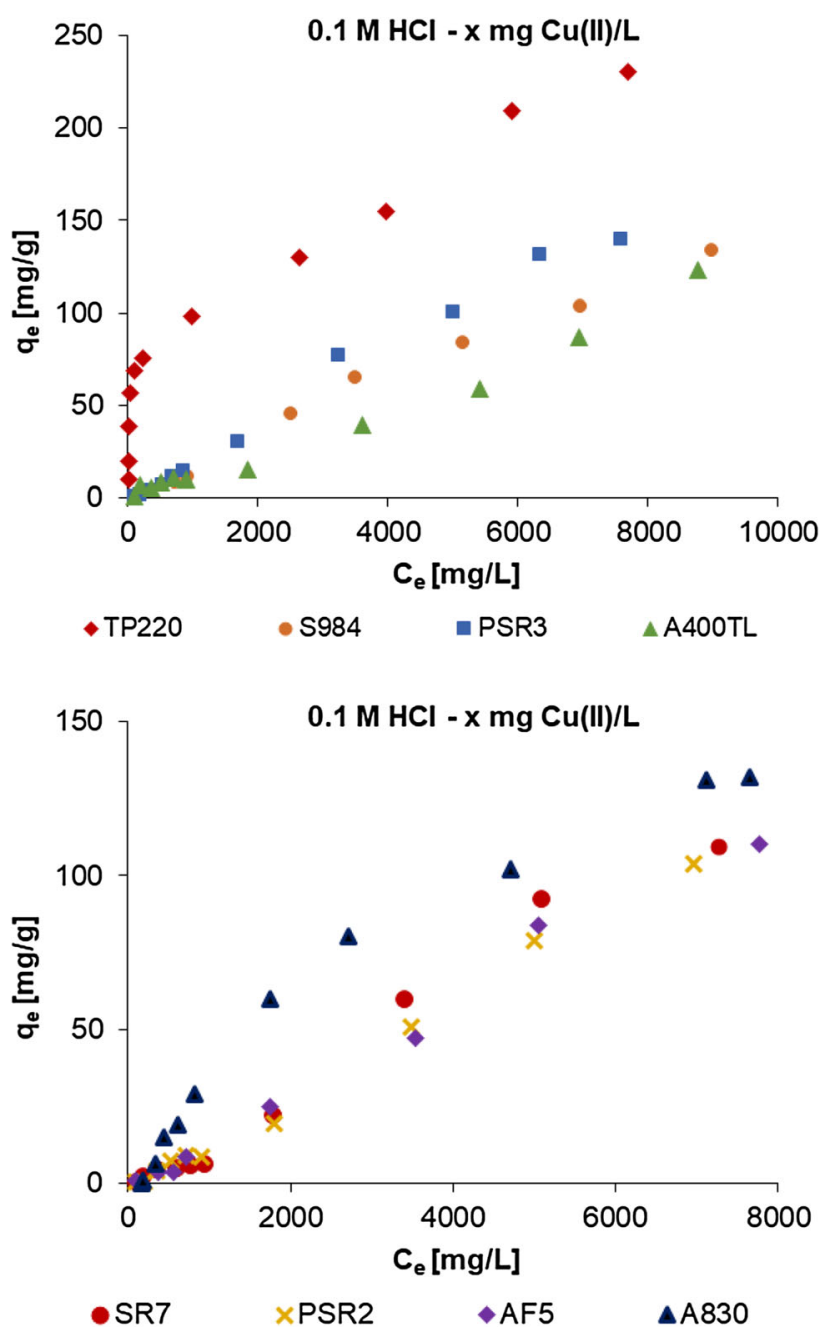

Figure 5 Effect of the initial copper(II) concentration on sorption capacity (plot $q_{\mathrm{e}}$ vs. $C_{\mathrm{e}}$ ) from $0.1 \mathrm{M} \mathrm{HCl}$ solutions (experimental conditions: $\quad m_{j}=0.5 \pm 0.0005 \mathrm{~g}, \quad V=0.05 \mathrm{~L}, \quad C_{\mathrm{o}}=100 \quad-$ $10000 \mathrm{mg} / \mathrm{L}, V_{\text {as }}=180 \mathrm{spm}, A=8, T=$ ambient, $t=24 \mathrm{~h}$ ). 
Based on the obtained experimental values capacities, the ion exchangers were placed in the following selectivity series: Lewatit MonoPlus TP 220 (230.2 mg/g) 》 Dowex PSR 3 (140 mg/g) > Purolite S $984(133.5 \mathrm{mg} / \mathrm{g}) \approx$ Purolite A $830(132 \mathrm{mg} / \mathrm{g}) \approx$ Dowex PSR $2(131 \mathrm{mg} / \mathrm{g})>$ Purolite A $400 \mathrm{TL}$ $(123.2 \mathrm{mg} / \mathrm{g})>$ Lewatit SR $7 \quad(118.3 \mathrm{mg} / \mathrm{g}) \approx$ Lewatit AF $5(117.8 \mathrm{mg} / \mathrm{g})$. As it was found, Lewatit MonoPlus TP 220 was the most efficient for copper(II) ions removal; therefore, for this ion exchanger the two most commonly used isotherm models such as Freundlich and Langmuir ones were applied. Description of these models together with the graphical presentation of isotherm curves as well as the values of calculated parameters is shown in Table 3 [41, 42]. The adsorption parameters were obtained using the linear regression technique and were calculated from the slope and intercept of the plots of $\log q_{\mathrm{e}}$ versus $\log C_{\mathrm{e}}$ (Langmuir isotherm) and $C_{\mathrm{e}} / q_{\mathrm{e}}$ versus $C_{\mathrm{e}}$ (Freundlich isotherm).

Comparing the values of determination coefficients of both models, the higher values were obtained using the Langmuir model $\left(R^{2}=0.949\right)$ than the Freundlich one. The experimental maximum sorption capacity calculated from Langmuir model is high $\left(Q_{0}=221.43 \mathrm{mg} / \mathrm{g}\right)$ and close to the experimental one $(230.2 \mathrm{mg} / \mathrm{g})$ indicating favourable sorption and good fitting of the experimental results with the Langmuir model (see fitting plot located in Table 3). The nature of the sorption (favourable, unfavourable, irreversible) was considered by the shape of the isotherm curve and by the dimensionless constant, $R_{\mathrm{L}}$ $\left(R_{L}=1 /\left(1+b C_{o}\right)\right)$. Based on the $R_{\mathrm{L}}$ parameter which was equal to 0.825 and the following conditions: $R_{\mathrm{L}}$ $=0-1$-favourable, $R_{\mathrm{L}}>1$ - unfavourable, $R_{\mathrm{L}}=1$ the linear isotherm, $R_{\mathrm{L}}=0$-the irreversible can be concluded that the $\mathrm{Cu}$ (II) sorption on Lewatit MonoPlus TP220 is favourable. The obtained results are in agreement with the literature ones [10, 43-45] which also indicate that the $\mathrm{Cu}$ (II) sorption on the other sorbents is well described by the Langmuir isotherm and/or Freundlich models and the favourable sorption is observed, e.g.: $\mathrm{Cu}$ (II) sorption on brushite calcium phosphate-the Langmuir isotherm, $R^{2}=0.999, Q_{0}=343.64 \mathrm{mg} / \mathrm{g}$ [43] or $\mathrm{Cu}(\mathrm{II})$ sorption on marine macro green algae, Halimeda gracilis-the Langmuir isotherm, $R^{2}=0.998, Q_{0}=38.46 \mathrm{mg} / \mathrm{g}$ [44], etc. As was mentioned by Buracov et al. [45] in the review paper concerning sorption of heavy metal ions on conventional and nanostructures materials, the adsorption of heavy metal ions can be described by the Langmuir and Freundlich isotherm models but for heavy metal cations sorption the Freundlich model has frequently proved superior to the Langmuir one. On the other hand, in another review [46], the cited examples show that the Langmuir isotherm is more suitable for $\mathrm{Cu}$ (II) sorption description. The analysis of the sorption capacities values presented in the literature, e.g. review papers $[10,45,46]$, shows that Lewatit MonoPlus TP 220 possesses higher or much higher capacity compared to that of the other ion exchangers (this paper), low cost adsorbents [10] and carbon adsorbents [46].

\section{Sorption of heavy metal ions from two- or three-component solutions}

Heavy metal ions sorption on eight ion exchangers was performed, and the results were published e.g. in [31-34, 47-49] and are presented in this paper. As it was proved Lewatit MonoPlus TP 220 is an efficient sorbent for noble metal ions removal (Pd(II), Pt(IV) and $\mathrm{Au}(\mathrm{III}))$, particularly for $\mathrm{Pd}(\mathrm{II})$ as well as for $\mathrm{Cu}(\mathrm{II}), \mathrm{Co}(\mathrm{II}), \mathrm{Ni}(\mathrm{II}), \mathrm{Zn}$ (II) removal, especially for $\mathrm{Cu}(\mathrm{II})$. Due to this fact sorption was also carried out from the two-component solutions containing $\mathrm{Pd}(\mathrm{II})$ and $\mathrm{Cu}(\mathrm{II})(\mathrm{Pd}(\mathrm{II})-\mathrm{Cu}(\mathrm{II})$, eight ion exchangers) and three-component solutions (Pd(II), $\mathrm{Pt}(\mathrm{IV}), \mathrm{Au}(\mathrm{III})$; Lewatit MonoPlus TP 220).

The results of $\mathrm{Cu}(\mathrm{II})$ sorption from two-component solutions and their comparison to those obtained from single solutions were analysed and are depicted in Fig. 6 (chosen examples) and Table 4.

The presented results lead to the following observation:

- the effectiveness of $\mathrm{Cu}(\mathrm{II})$ and $\mathrm{Pd}(\mathrm{II})$ ions removal from the single and two-component solutions is slightly (Lewatit MonoPlus TP 220) or significantly different for the remaining tested ion exchangers,

- in the case of the ion exchanger Lewatit MonoPlus TP 220 (Fig. 6a) for which the $\mathrm{Pd}(\mathrm{II})$ and $\mathrm{Cu}(\mathrm{II})$ removal efficiency from single solutions is high (removal efficiency is equal to $100 \%$ or slightly lower, $q_{\mathrm{t}}$ values in the range $9.1-10 \mathrm{mg} / \mathrm{g}$ ) no significant changes of this efficiency in the twocomponent solutions are observed. The competitive effect of these heavy metal ions is not pointed out, and the coordination mechanism using $\mathrm{N}$ 

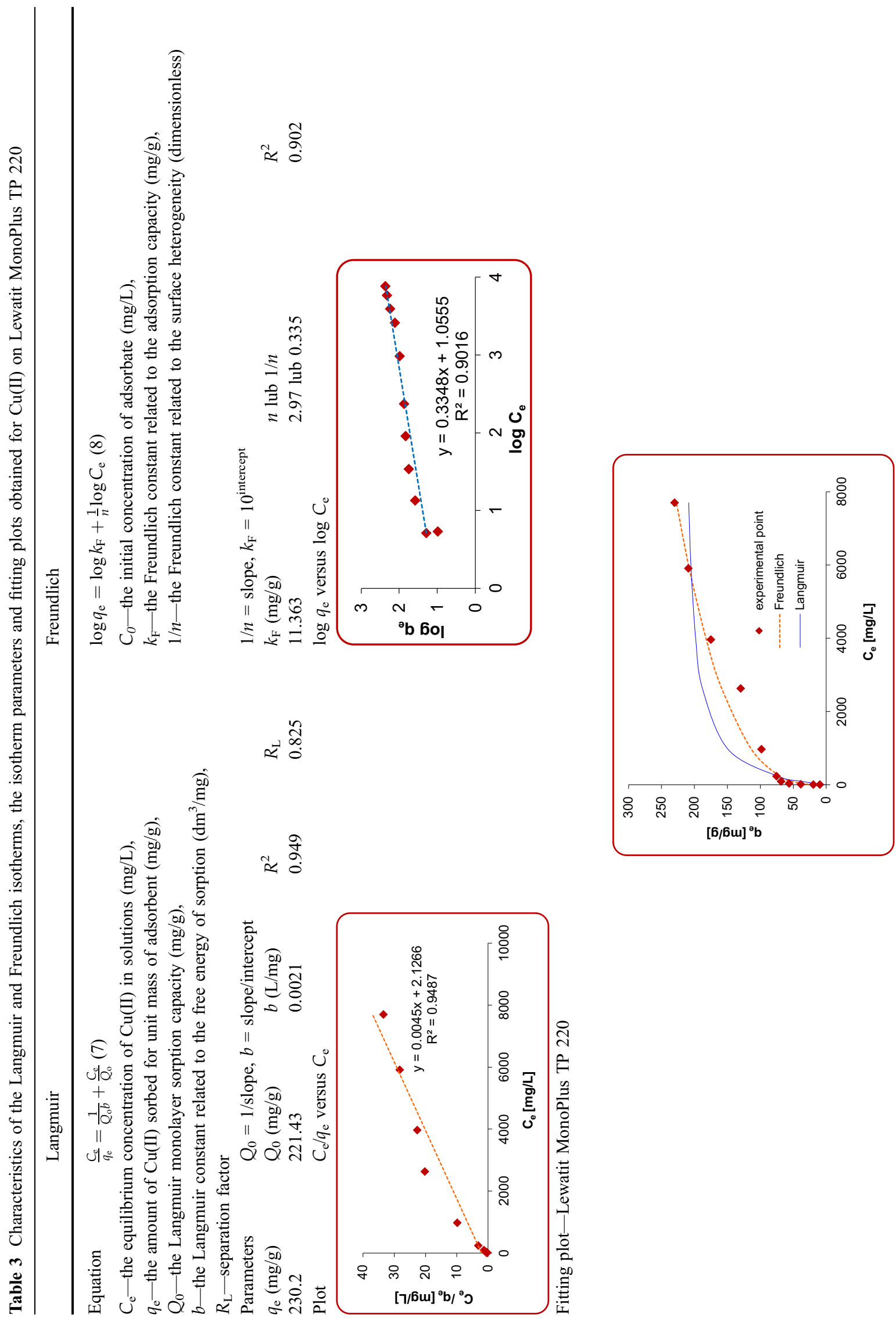
(a)
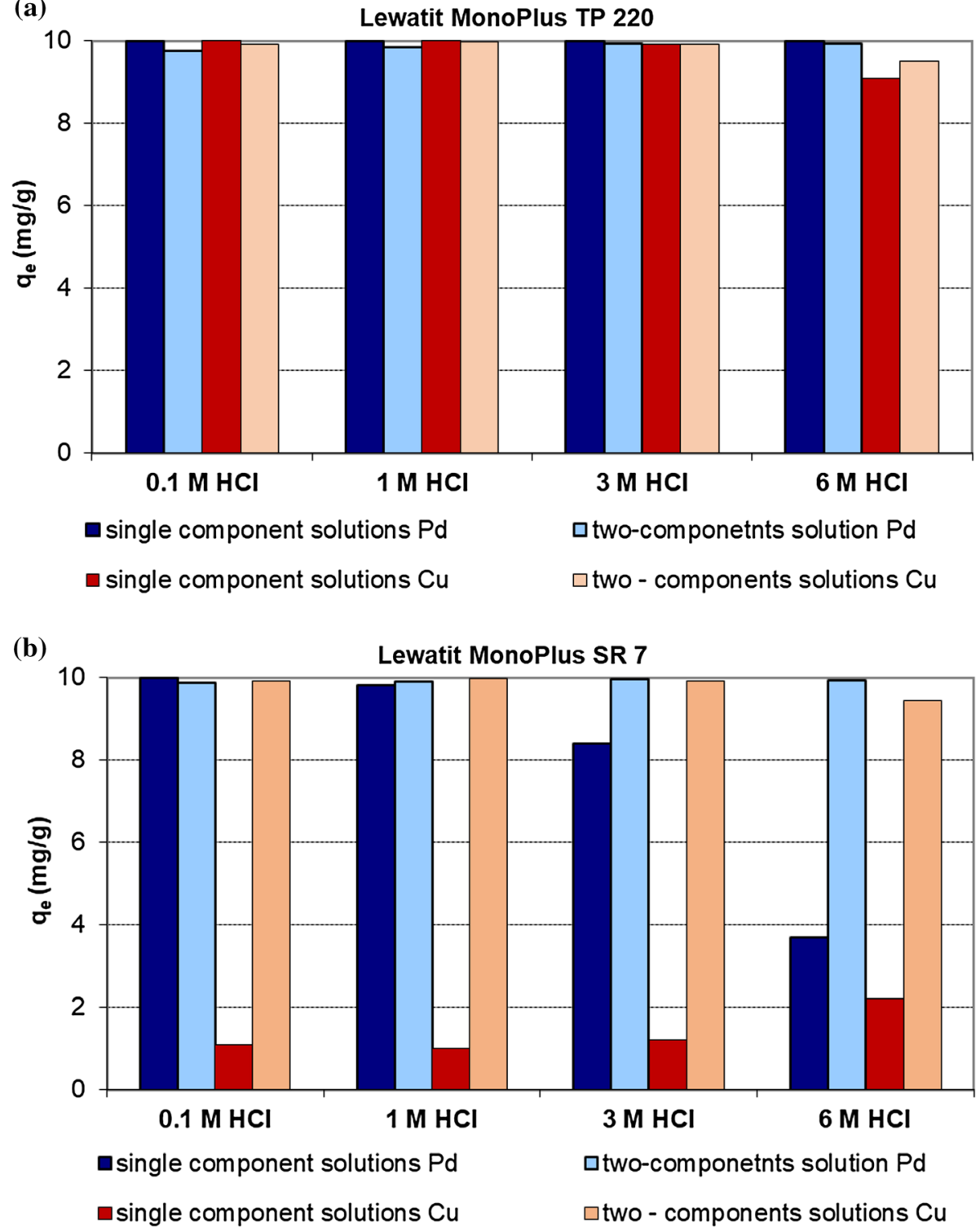

Figure 6 Comparison of the amount of heavy metal ions (Pd(II) or Cu(II)) sorbed on a Lewatit MonoPlus TP 220 and b Lewatit MonoPlus SR 7 from acidic solutions (experimental conditions: $m_{j}=0.5 \pm 0.0005 \mathrm{~g}, \quad V=0.05 \mathrm{~L}, \quad C_{\mathrm{o}}=100 \mathrm{mg} \mathrm{M}(\mathrm{II}) / \mathrm{L}$, $V_{\text {as }}=180 \mathrm{spm}, A=8, T=$ ambient, $t=24 \mathrm{~h}$ ).

donor atoms of the bis-picolylamine functional groups takes place [31],

- in all other cases Pd(II) sorption efficiency or amount of $\mathrm{Pd}$ (II) sorbed from single solutions is high, quantitative removal from the diluted acidic solution is observed, and then the values of $q_{\mathrm{t}}$ decrease with the hydrochloric acid increase; opposite situation is observed in the case of $\mathrm{Cu}$ (II) sorption from single solutions $\left(q_{\mathrm{t}}\right.$ values usually increase with the hydrochloric acid concentration increase) [31-34, 47-49]. The diversified effectiveness of the $\mathrm{Cu}(\mathrm{II})$ and $\mathrm{Pd}(\mathrm{II})$ removal process is related to the form in which these metals exist in the solution under discussion which is dependent on the acidity of the medium, the total concentration of the chloride ions and temperature. In acidic solutions $(0.1-6 \mathrm{M} \mathrm{HCl})$, various forms of $\mathrm{Cu}(\mathrm{II})$ and $\mathrm{Pd}(\mathrm{II})$ chlorocomplexes can be formed or they can exist in the form of cations or inert chlorocomplexes [31, 50-53]: 
Table 4 Comparison of the amount of heavy metal ions sorbed on the ion exchangers under discussion from single and two-component solutions

\begin{tabular}{|c|c|c|c|c|c|c|c|c|c|c|c|c|}
\hline \multirow[t]{2}{*}{ Systems } & \multicolumn{2}{|c|}{ Single solutions } & \multirow[t]{2}{*}{ Ref. } & \multicolumn{2}{|c|}{$\begin{array}{l}\text { Two-component } \\
\text { solutions }\end{array}$} & \multirow[t]{2}{*}{ Ref. } & \multicolumn{2}{|c|}{ Single solutions } & \multirow[t]{2}{*}{ Ref. } & \multicolumn{2}{|c|}{$\begin{array}{l}\text { Two-component } \\
\text { solutions }\end{array}$} & \multirow[t]{2}{*}{ Ref. } \\
\hline & $\begin{array}{l}q_{\mathrm{t}}(\mathrm{mg} / \\
\mathrm{g}) \operatorname{Pd}(\mathrm{II})\end{array}$ & $\begin{array}{l}q_{\mathrm{t}}(\mathrm{mg} / \\
\mathrm{g}) \mathrm{Cu}(\mathrm{II})\end{array}$ & & $\begin{array}{l}q_{\mathrm{t}}(\mathrm{mg} / \\
\mathrm{g}) \operatorname{Pd}(\mathrm{II})\end{array}$ & $\begin{array}{l}q_{\mathrm{t}}(\mathrm{mg} / \\
\mathrm{g}) \mathrm{Cu}(\mathrm{II})\end{array}$ & & $\begin{array}{l}q_{\mathrm{t}}(\mathrm{mg} / \\
\mathrm{g}) \operatorname{Pd}(\mathrm{II})\end{array}$ & $\begin{array}{l}q_{\mathrm{t}}(\mathrm{mg} / \\
\mathrm{g}) \mathrm{Cu}(\mathrm{II})\end{array}$ & & $\begin{array}{l}q_{\mathrm{t}}(\mathrm{mg} / \\
\mathrm{g}) \operatorname{Pd}(\mathrm{II})\end{array}$ & $\begin{array}{l}q_{\mathrm{t}}(\mathrm{mg} / \\
\mathrm{g}) \mathrm{Cu}(\mathrm{II})\end{array}$ & \\
\hline & \multicolumn{5}{|c|}{ Lewatit MonoPlus TP220 } & & \multicolumn{5}{|c|}{ Dowex PSR 3} & \multirow{5}{*}{$\begin{array}{l}\text { This } \\
\text { paper }\end{array}$} \\
\hline $0.1 \mathrm{M} \mathrm{HCl}$ & 10.0 & 10.0 & \multirow[t]{5}{*}[15]{} & 9.7 & 9.9 & \multirow[t]{4}{*}{$\begin{array}{l}\text { This } \\
\text { paper }\end{array}$} & 10.0 & 0.8 & \multirow[t]{4}{*}[17]{} & 10.0 & 4.6 & \\
\hline $1.0 \mathrm{M} \mathrm{HCl}$ & 10.0 & 10.0 & & 9.8 & 10.0 & & 9.7 & 1.2 & & 9.7 & 4.5 & \\
\hline $3.0 \mathrm{M} \mathrm{HCl}$ & 10.0 & 9.9 & & 9.9 & 9.9 & & 7.9 & 2.3 & & 8.1 & 4.8 & \\
\hline $6.0 \mathrm{M} \mathrm{HCl}$ & 10.0 & 9.1 & & 9.9 & 9.5 & & 5.2 & 2.4 & & 2.1 & 5.2 & \\
\hline & \multicolumn{4}{|c|}{ Lewatit SR 7} & & & \multicolumn{5}{|c|}{ Purolit A $400 \mathrm{TL}$} & \multirow{5}{*}{$\begin{array}{l}\text { This } \\
\text { paper }\end{array}$} \\
\hline $0.1 \mathrm{M} \mathrm{HCl}$ & 10.0 & 1.1 & $\begin{array}{l}\text { [32], this } \\
\text { paper }\end{array}$ & 9.9 & 9.9 & $\begin{array}{l}\text { This } \\
\text { paper }\end{array}$ & 10.0 & 4.7 & [33] & 10.0 & 4.7 & \\
\hline $1.0 \mathrm{M} \mathrm{HCl}$ & 9.8 & 1.0 & & 9.9 & 10.0 & & 9.8 & 4.8 & & 9.6 & 4.6 & \\
\hline $3.0 \mathrm{M} \mathrm{HCl}$ & 8.4 & 1.2 & & 10.0 & 9.9 & & 9.0 & 4.9 & & 7.7 & 4.7 & \\
\hline $6.0 \mathrm{M} \mathrm{HCl}$ & 3.7 & 2.2 & & 9.9 & 9.4 & & 7.1 & 4.8 & & 3.9 & 5.3 & \\
\hline & \multicolumn{6}{|c|}{ Purolite S 984} & \multicolumn{3}{|c|}{ Lewatit AF 5} & & & \multirow{5}{*}[18]{} \\
\hline $0.1 \mathrm{M} \mathrm{HCl}$ & 10.0 & 0.0 & {$[16]$} & 10.0 & 5.1 & $\begin{array}{l}\text { This } \\
\text { paper }\end{array}$ & 10.0 & 1.2 & {$[18]$} & 10.0 & 5.1 & \\
\hline $1.0 \mathrm{M} \mathrm{HCl}$ & 9.8 & 0.0 & & 9.7 & 4.8 & & 9.8 & 1.7 & & 9.6 & 5.3 & \\
\hline $3.0 \mathrm{M} \mathrm{HCl}$ & 8.8 & 0.0 & & 7.7 & 5.0 & & 9.3 & 2.0 & & 8.3 & 5.3 & \\
\hline $6.0 \mathrm{M} \mathrm{HCl}$ & 7.7 & 1.8 & & 5.6 & 5.8 & & 8.2 & 1.9 & & 6.2 & 5.7 & \\
\hline & \multicolumn{5}{|c|}{ Dowex PSR 2} & & \multicolumn{3}{|c|}{ Purolit A 830} & & & \\
\hline $0.1 \mathrm{M} \mathrm{HCl}$ & 10.0 & 0.9 & {$[17]$} & 10.0 & 4.9 & $\begin{array}{l}\text { This } \\
\text { paper }\end{array}$ & 10.0 & 1.5 & {$[34]$} & 10.0 & 4.8 & \multirow[t]{4}{*}{$\begin{array}{l}\text { This } \\
\text { paper }\end{array}$} \\
\hline $1.0 \mathrm{M} \mathrm{HCl}$ & 9.8 & 1.1 & & 9.5 & 4.8 & & 9.8 & 1.2 & & 9.6 & 4.8 & \\
\hline $3.0 \mathrm{M} \mathrm{HCl}$ & 9.0 & 1.1 & & 6.5 & 4.9 & & 8.1 & 1.2 & & 7.6 & 4.8 & \\
\hline $6.0 \mathrm{M} \mathrm{HCl}$ & 5.0 & 1.5 & & 1.4 & 5.1 & & 6.6 & 3.5 & & 5.9 & 6.0 & \\
\hline
\end{tabular}

- $\mathrm{Cu}(\mathrm{II}):\left[\mathrm{CuCl}_{4}\right]^{2-}$ - exists when $\mathrm{HCl}$ concentration is in the range $1-4 \mathrm{~mol} / \mathrm{L} ;\left[\mathrm{Cu}_{2} \mathrm{Cl}_{6}\right]^{2-}-$ exists when $\mathrm{HCl}$ concentration is in the range 5-10 mol/L; decrease in acidity results in $\left[\mathrm{Cu}\left(\mathrm{H}_{2} \mathrm{O}\right)_{6}\right]^{2+}$ formation; in the $\mathrm{Cl}^{-}$ions presence $(0.5-1 \mathrm{~mol} / \mathrm{L})$ - weaker acidic media the following reaction takes place: $2\left[\mathrm{CuCl}_{2}\right] \leftrightarrow$ $\left[\mathrm{CuCl}_{3}\right]^{-}+[\mathrm{CuCl}]^{+}[31,50-52]$,

- $\mathrm{Pd}(\mathrm{II}):\left[\mathrm{PdCl}_{4}\right]^{2-}$ - exists when $\mathrm{HCl}$ concentration is higher than $0.1 \mathrm{~mol} / \mathrm{L}$ [31]; with the decreasing acidity of the solution, $\left[\mathrm{PdCl}_{4}\right]^{2-}$ ions are aquatized to $\left[\mathrm{Pd}\left(\mathrm{H}_{2} \mathrm{O}\right) \mathrm{Cl}_{3}\right]^{-},\left[\mathrm{Pd}\left(\mathrm{H}_{2}\right.\right.$ $\left.\mathrm{O})_{2} \mathrm{Cl}_{2}\right]$ and $\left[\mathrm{Pd}\left(\mathrm{H}_{2} \mathrm{O}\right)_{3} \mathrm{Cl}\right]^{+}$forms [54].

More details of such sorption behaviour in the single solutions can be found in the previously published papers [31-34, 47-49]. It is known that the removal efficiency is also strongly dependent on the functional groups of the ion exchangers that means types of the ion exchangers. Due to this fact, the mechanism of sorption is different (see Fig. 7).

- In the binary solutions, $\mathrm{Pd}(\mathrm{II})-\mathrm{Cu}(\mathrm{II}) q_{\mathrm{t}}$ values of $\operatorname{Pd}($ II) usually remain unchangeable or decrease compared to the single solutions, whereas the $q_{\mathrm{t}}$ values of $\mathrm{Cu}$ (II) usually slightly or significantly increase (except for Lewatit MonoPlus SR 7-in this case both $\mathrm{Pd}(\mathrm{II})$ and $\mathrm{Cu}(\mathrm{II})$ ions sorption efficiency increases). During the simultaneous sorption of $\mathrm{Pd}(\mathrm{II})$ and $\mathrm{Cu}(\mathrm{II})$ ions from the weak and strong acidic solutions, the presence of $\mathrm{Pd}(\mathrm{II})$ results in the $\mathrm{Cu}(\mathrm{II})$ removal efficiency increase that means that the joint action of simultaneously sorbed $\mathrm{Pd}(\mathrm{II})$ and $\mathrm{Cu}(\mathrm{II})$ ions results in increased selectivity of ion exchange resins towards copper(II) ions. Such behaviour may result from the acidic effect, affecting the ion exchange resin phase and facilitating the sorption of more 


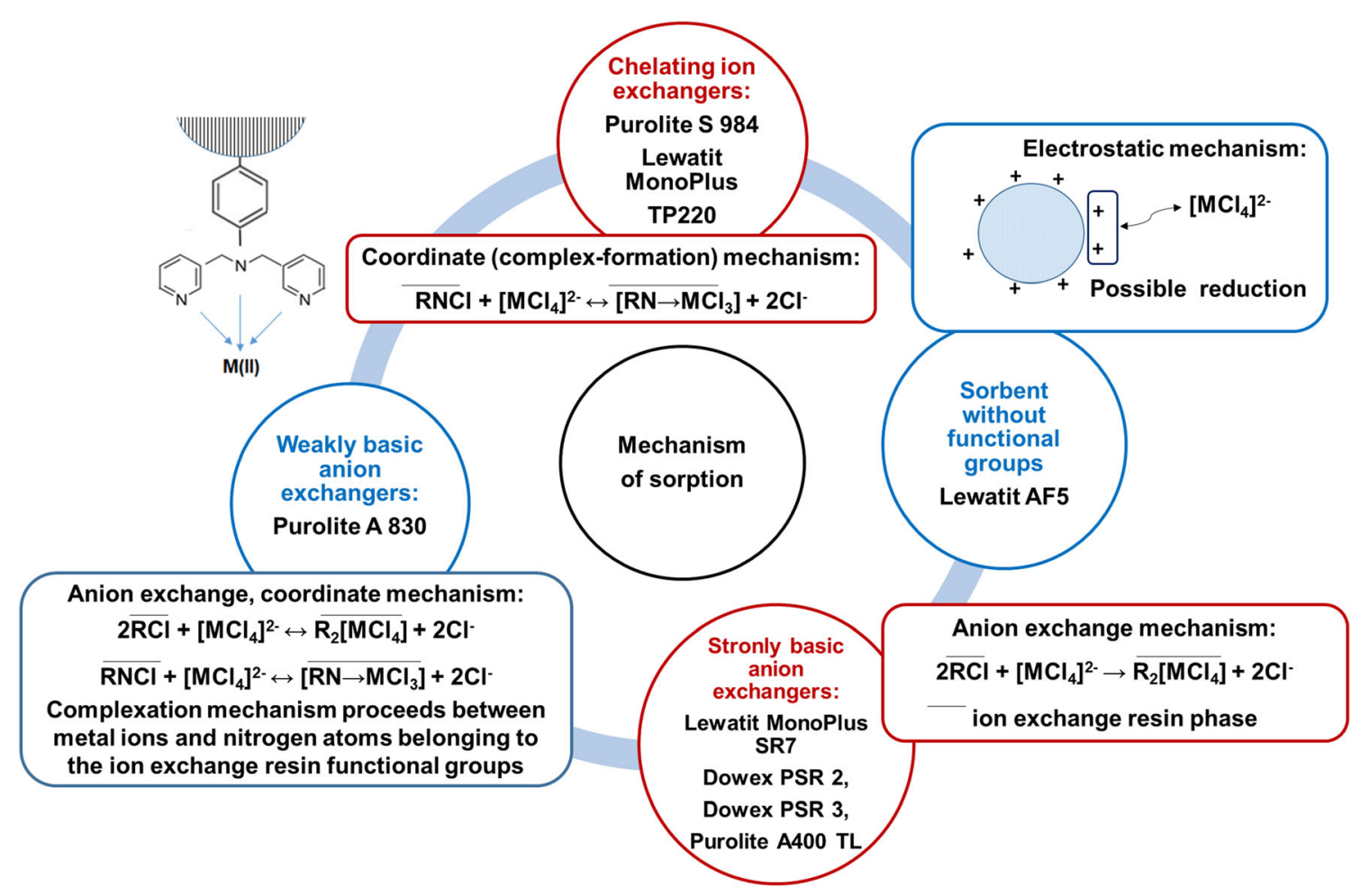

Figure 7 Mechanism of heavy metal ions ( $\mathrm{Pd}(\mathrm{II}), \mathrm{Cu}(\mathrm{II})$ ) sorption depending on the types of ion exchangers.

stable anion complexes. Kononova et al. [51] also examined ion exchangers selectivity towards heavy metal ions such as $\mathrm{Cu}$ (II) and $\mathrm{Zn}$ (II) (binary acidic solutions- $\mathrm{HCl}$ solutions). As it was found $\mathrm{Cu}(\mathrm{II})$, sorption efficiency as well as selectivity of anion exchange resins increases in the presence of $\mathrm{Zn}$ (II) ions in the case of weak acidic solutions and strong acidic solutions for strongly basic anion exchanger, which was explained by the acidic effect and complex mechanism.

Lewatit MonoPlus TP 220 was also applied in sorption of noble metal ions $\mathrm{Pd}(\mathrm{II}), \mathrm{Pt}(\mathrm{IV})$ and $\mathrm{Au}(\mathrm{III})$ from three-component solutions in which the metal concentration was in the range from 5 to $100 \mathrm{mg} / \mathrm{L}$. The results are presented in Fig S2 (Supplementary Materials). As can be seen from the results in the system of the same concentrations of all heavy metal ions, the selectivity series is as follows: $\mathrm{Au}(\mathrm{III}) \geq$ $\operatorname{Pt}(\mathrm{IV}) \geq \operatorname{Pd}(\mathrm{II})$, but the differences between the $q_{\mathrm{t}}$ values are not so high. The high affinity of Lewatit TP MonoPlus TP 220 towards gold complexes could be attributed to high mobility of $\mathrm{AuCl}_{4}{ }^{-}$through the resin network and the presence of free electron pairs on the ligand (ion exchangers possess three nitrogen donor atoms). The smallest charge density of $\mathrm{Au}(\mathrm{III})$ causes that the functional groups of ion exchanger resin favoured interaction with gold chlorocomplexes [55]. Moreover, the $q_{\mathrm{t}}$ values increase with the metal ions concentration increase (the initial metal concentration provides an important driving force). The percentage removal efficiency ( $\% \mathrm{R})$ is in the range from 93.4 to $99.6 \%$ for Pt(IV), from 90 to $99.1 \%$ for $\mathrm{Pd}(\mathrm{II})$ and from 95.4 to $100 \%$ for $\mathrm{Au}(\mathrm{III})$. In the case of an excess of one heavy metal ions during the sorption on Lewatit MonoPlus TP 220, a slight decrease in $q_{\mathrm{t}}$ values for $\mathrm{Pt}(\mathrm{IV})$ with the $\mathrm{Pd}(\mathrm{II})$ and $\mathrm{Au}(\mathrm{III})$ ions concentration increase was observed. The $\% R$ values decrease from 99\% (100 mg Pt(IV)/L; $5 \mathrm{mg} \mathrm{Pd(II)/L;}$ $5 \mathrm{mg} \mathrm{Au}(\mathrm{III}) / \mathrm{L}$ ) to $97.2 \%$ (100 mg Pt(IV)/L; $80 \mathrm{mg}$ $\mathrm{Pd}(\mathrm{II}) / \mathrm{L} ; 80 \mathrm{mg} \mathrm{Au}(\mathrm{III}) / \mathrm{L}$ ), whereas in the case of solutions with an excess of two heavy metal ions $\% R$ values of $\mathrm{Pt}(\mathrm{IV})$ slightly increase with the $\mathrm{Pd}(\mathrm{II})$ concentration increase; $\% R$ values increase from 97.7\% (100 mg Pt(IV)/L; $5 \mathrm{mg} \mathrm{Pd}(\mathrm{II}) / \mathrm{L} ; 100 \mathrm{mg}$ $\mathrm{Au}(\mathrm{III}) / \mathrm{L}$ ) to $99.1 \%$ (100 mg Pt(IV)/L; $80 \mathrm{mg} \mathrm{Pd(II)/}$ $\mathrm{L} ; 100 \mathrm{mg} \mathrm{Au}(\mathrm{III}) / \mathrm{L})$. The changes of $q_{\mathrm{t}}$ and $\% R$ values indicate that the competitive effect between heavy metal ions of sorption sites could take place 
but does not influence significantly the sorption yield and could be neglected. As it was mentioned in the paper [31], Lewitit MonoPlus TP 220 ion exchanger preference towards specific heavy metal ion from the mixture is not observed. For $\mathrm{Pd}(\mathrm{II})-\mathrm{Pt}(\mathrm{IV})-\mathrm{Au}(\mathrm{III})$ solutions of the same heavy metal ions concentration (concentration of each heavy metal ions from 5 to $80 \mathrm{~g} / \mathrm{L}$ ) sorption and desorption cycles (three repetitions) used as the eluting agents, the mixture of thiourea with $0.1 \mathrm{M} \mathrm{HCl}$, sodium hydroxide and ammonium hydroxide selected by the desorption efficiency (\%D) from the single solutions [31] indicates that using $\mathrm{NaOH}$ solutions $\mathrm{Pt}(\mathrm{IV})$ desorption was observed (e.g. \%D1 for Pt(IV) was from 39.6\% to $66.5 \%$ and a decrease in the third desorption step), whereas that for $\mathrm{Pd}(\mathrm{II})$ and $\mathrm{Au}(\mathrm{III})$ was equal to 0 or was very low (\% D1, D2, D3 from 0 to $2.8 \%$ ), which indicates that $\mathrm{Pt}(\mathrm{IV})$ separation could be possible. The other mentioned above eluting agents give $\% \mathrm{D} 1$ in the range: $95.8-32.9 \%(0.1 \mathrm{M}$ thiourea $+0.1 \mathrm{M} \mathrm{HCl})$ and $50.2-14 \%$ ( $3 \mathrm{M} \mathrm{NH}_{4} \mathrm{OH}$ ) for all heavy metal ions present in the solutions. High desorption efficiency of gold is related to the displacement principle. Introducing an anion with higher affinity to resin compared with the adsorbed gold chlorocomplex results in adsorption equilibrium shifting to the left. The complex of gold of positive charge with thiourea starts to form $\mathrm{Au}\left[\mathrm{CS}\left(\mathrm{NH}_{2}\right)_{2}\right]_{2}^{+}$. The resin has weak affinity to the newly formed species; thus, it is able to efficiently strip gold from ion exchange resin in the presence of the weak eluent, e.g. $\mathrm{HCl}$ [55]. The sorption efficiency in the second and third steps (\%S2, \%S3) sometimes decreases, but the highest sorption yield decrease in \%S2 and \%S3 was observed for $\mathrm{Au}$ (III) (desorption $0.1 \mathrm{M}$ thiourea + $0.1 \mathrm{M} \mathrm{HCl})$. The \%S2, \%S3 decrease is related to the fact that desorption after first cycle is not quantitative and some heavy metal ions remained on the resins and the adsorption sites are occupied. The reduction in sorption ability of gold could be also related to osmotic shock produced by repeated elution in acidic media (breakage of the resin beads), but this hypothesis needs additional analysis. Moreover, the decomposition of thiourea in acid solutions occurs which makes the desorption less efficient [56].

\section{Copper(II) sorption by Lewatit MonoPlus TP 220 using the batch method: kinetic studies}

The kinetic investigations are very important due to possible prediction of the rate at which toxic copper metal ions are removed from aqueous, acidic solutions and are helpful for understanding the mechanism of $\mathrm{Cu}(\mathrm{II})$ sorption reactions. Kinetic sorption experiments were performed to establish the effect of phase contact time on the sorption of copper(II) ions on Lewatit MonoPlus TP 220. The pseudo-first-order (PFO) and pseudo-second-order (PSO) kinetic equations were used to describe the kinetic curves whose characteristics are presented in Fig. 8. The plots of $\log \left(q_{\mathrm{e}}-q_{\mathrm{t}}\right)$ versus $t$ (PFO model) and the plots $t / q_{\mathrm{t}}$ versus $t$ (PSO model) were obtained and are presented in Fig. 3S. As can be seen, PFO equation fails at the data matching stage; instead of a straight line, a bent curve is obtained. The applicability of these models (error analysis to evaluate the best fitted model for $\mathrm{Cu}$ (II) sorption) was assessed based on the normalized standard deviation $\Delta q(\%)$, Chi-square test $\left(\chi^{2}\right)$ and the coefficient of determination $\mathrm{R}^{2}$. The best-fit model is the one which possesses the lowest value of $\Delta q \%, \chi^{2}$ and the highest values of $R^{2}$ which is closer to unity. The normalized standard deviation $(\Delta q \%)$ and Chi square $\left(\chi^{2}\right)$ parameters were calculated using the following mathematical expressions [54]:

$$
\begin{aligned}
& \Delta q \%=\sqrt{\frac{\sum\left[\left(q_{\mathrm{t}, \mathrm{exp}}-q_{\mathrm{t}, \mathrm{cal}}\right) / q_{\mathrm{t}, \mathrm{exp}}\right]^{2}}{n-1}} \times 100 \\
& \chi^{2}=\sum \frac{\left(q_{\mathrm{t}, \mathrm{exp}}-q_{\mathrm{t}, \mathrm{cal}}\right)^{2}}{q_{\mathrm{t}, \mathrm{cal}}}
\end{aligned}
$$

where $q_{\mathrm{t}, \exp }$ and $q_{\mathrm{t}, \mathrm{cal}}$ are the experimental and calculated (predicted) amounts of $\mathrm{Cu}$ (II) sorbed, and $n$ is the number of data points.

The results of kinetic models with their parameters, determination coefficient, normalized standard deviation values and the fitting plots of predicted and experimental $q_{\mathrm{t}}$ values are given in Table 5 for PSO and in Table S2 for PFO. As can be seen from Table 5 and Table S2, the kinetic rate of PFO $k_{1}$ decreases with the hydrochloric acid concentration increase, whereas in the case of PSO model these values first increase with the hydrochloric acid increase up to $1 \mathrm{M}$ and then decrease. The initial sorption rate $h$ changes with the hydrochloric acid concentration similar to $k_{2}$ 


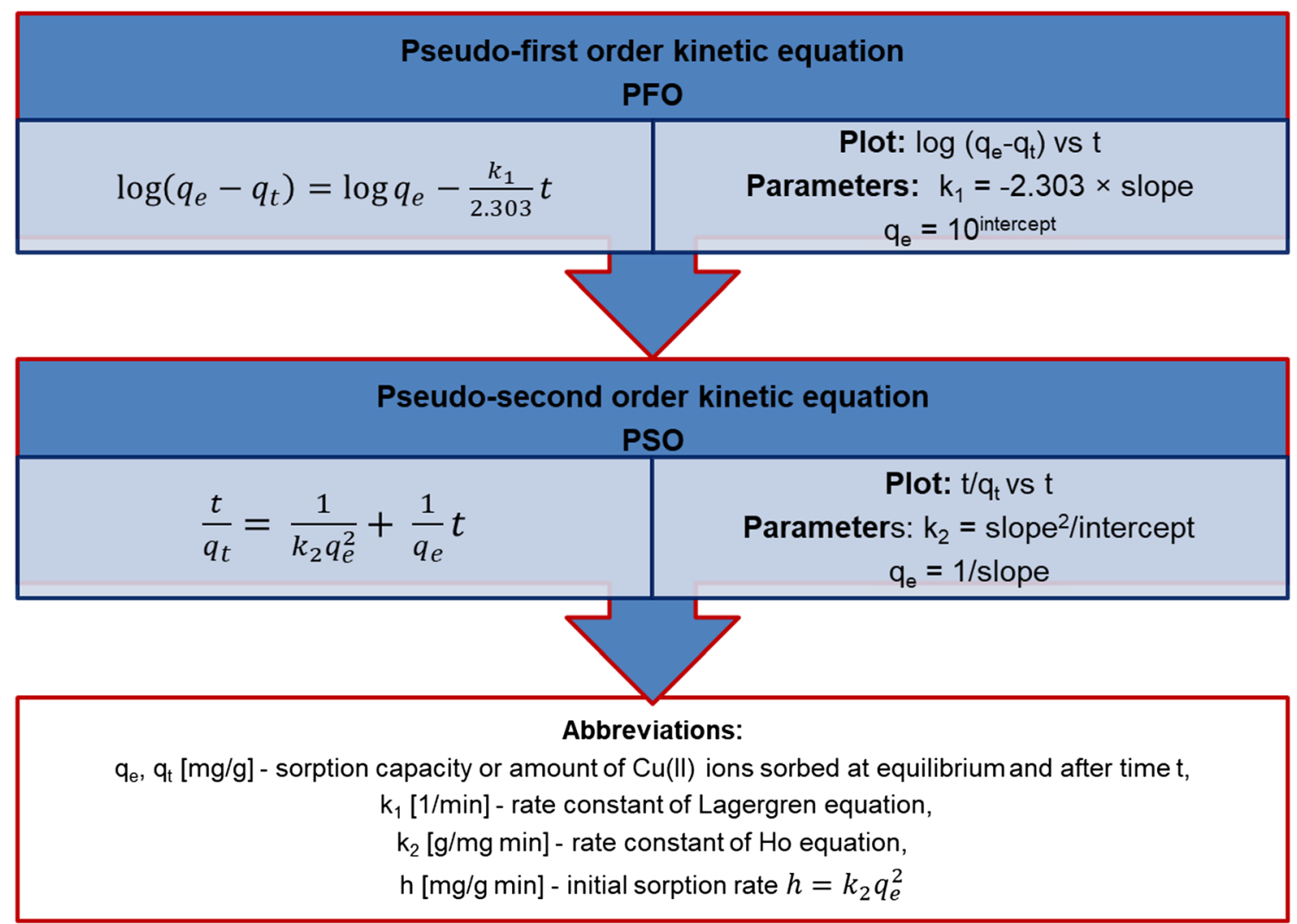

Figure 8 Pseudo-first-order (PFO) and pseudo-second-order (PSO) kinetic model characteristics applied for Cu(II) sorbed on Lewatit MonoPlus TP 220.

values, at first increases up to $1 \mathrm{M}$ and then decreases. Changes of $k_{1}$ and $k_{2}$ parameters with hydrochloric acid concentration increase are related to the fact that at the beginning of the sorption due to a high number of empty active sites the adsorption is fast in the dilute solutions and the $h$ parameter increase. Then with the increase in $\mathrm{HCl}$ concentration the total concentration of ions in the solution also increases, whereas the number of adsorption sites decreases resulting in that the solution is more crowded and the speed of diffusion decreases. After that, the initial sorption rate and $k_{2}$ values decrease. Shape of kinetic curves indicates that the time required to reach system equilibrium is short. This fact suggests that rather surface adsorption takes place than the surface diffusion of adsorbed particles into the pores of the adsorbent, but additional analysis and applications of so-called Boyd plot ( $q_{\mathrm{t}}$ vs. $t^{1 /}$ ${ }^{2}$ ) which has physical sense only for low surface coverings for $q_{\mathrm{t}}<q_{\mathrm{e}} / 3$ is needed to prove this hypothesis [55]. The pseudo-second-order kinetic model has much higher determination coefficient values $\left(R^{2}>0.999\right)$ compared to the values obtained using the PFO model $\left(R^{2}>0.902\right)$. Moreover, the sorption capacity value obtained experimentally for different hydrochloric acid concentrations, $q_{\mathrm{e}, \exp }$ was in a good agreement with the calculated one, $q_{\mathrm{e}, \mathrm{cal}}$ obtained by the PSO model e.g. $q_{\mathrm{e}, \exp }=9.98 \mathrm{mg} / \mathrm{g}$, $q_{\mathrm{e}, \mathrm{cal}}=10.38 \mathrm{mg} / \mathrm{g} \quad(0.1 \mathrm{M} \mathrm{HCl}, \quad \mathrm{PSO}), \quad q_{\mathrm{e}, \mathrm{cal}}$ $=5.58 \mathrm{mg} / \mathrm{g}(0.1 \mathrm{M} \mathrm{HCl}, \mathrm{PFO})$ or $q_{\mathrm{e}, \exp }=9.95 \mathrm{mg} / \mathrm{g}$, $q_{\mathrm{e}, \mathrm{cal}}=10.14 \mathrm{mg} / \mathrm{g}(1 \mathrm{M} \mathrm{HCl}, \mathrm{PSO}), q_{\mathrm{e}, \mathrm{cal}}=3.39 \mathrm{mg} /$ $\mathrm{g}(1 \mathrm{M} \mathrm{HCl}, \mathrm{PFO})$ and was much higher than that obtained from PFO model. The smaller values of calculated $q_{\mathrm{t}}$ in the case of PFO could result from random experimental errors and properties of the linear representation used. The impact of random experimental errors is crucial in the case of $\mathrm{PFO}$ equations, whereas that in the case of PSO is negligible, which results in limitation in PFO applicability. Taking into account the linear representation of $\mathrm{PFO}$ model $-\log \left(q_{\mathrm{e}}-q_{\mathrm{t}}\right)$ the difference between $q_{\mathrm{e}}$ and $q_{\mathrm{t}}$ during the adsorption progress decreases, whereas the value of $\log \left(q_{\mathrm{e}}-q_{\mathrm{t}}\right)$ increases. The impact of random errors will increase proportionally to the 
Table 5 Comparison of the kinetic parameters and the fitting plots obtained from the PSO models for Cu(II) removal on Lewatit MonoPlus TP 220

\begin{tabular}{|c|c|c|c|c|c|c|c|}
\hline \multirow[t]{2}{*}{ Systems } & \multirow[t]{2}{*}{$\begin{array}{l}q_{\text {e,exp }} \\
(\mathrm{mg} / \mathrm{g})\end{array}$} & \multicolumn{6}{|c|}{$\begin{array}{l}\text { Pseudo-second-order kinetic equation } \\
\text { PSO }\end{array}$} \\
\hline & & $\begin{array}{l}q_{2} \\
(\mathrm{mg} / \mathrm{g})\end{array}$ & $\begin{array}{l}k_{2} \\
(\mathrm{~g} / \mathrm{mg} \min )\end{array}$ & $\begin{array}{l}h \\
(\mathrm{mg} / \mathrm{g} \mathrm{min})\end{array}$ & $R^{2}$ & $\begin{array}{l}\Delta q \\
(\%)\end{array}$ & $\chi^{2}$ \\
\hline $0.1 \mathrm{M} \mathrm{HCl}$ & 9.98 & 10.38 & 0.012 & 1.34 & 0.999 & 12.53 & 0.22 \\
\hline $1 \mathrm{M} \mathrm{HCl}$ & 9.95 & 10.14 & 0.026 & 2.64 & 1.000 & 6.59 & 0.16 \\
\hline $3 \mathrm{M} \mathrm{HCl}$ & 9.87 & 10.06 & 0.023 & 2.32 & 1.000 & 4.78 & 0.09 \\
\hline $6 \mathrm{M} \mathrm{HCl}$ & 9.12 & 9.36 & 0.014 & 1.22 & 1.000 & 8.23 & 0.21 \\
\hline
\end{tabular}

Fitting
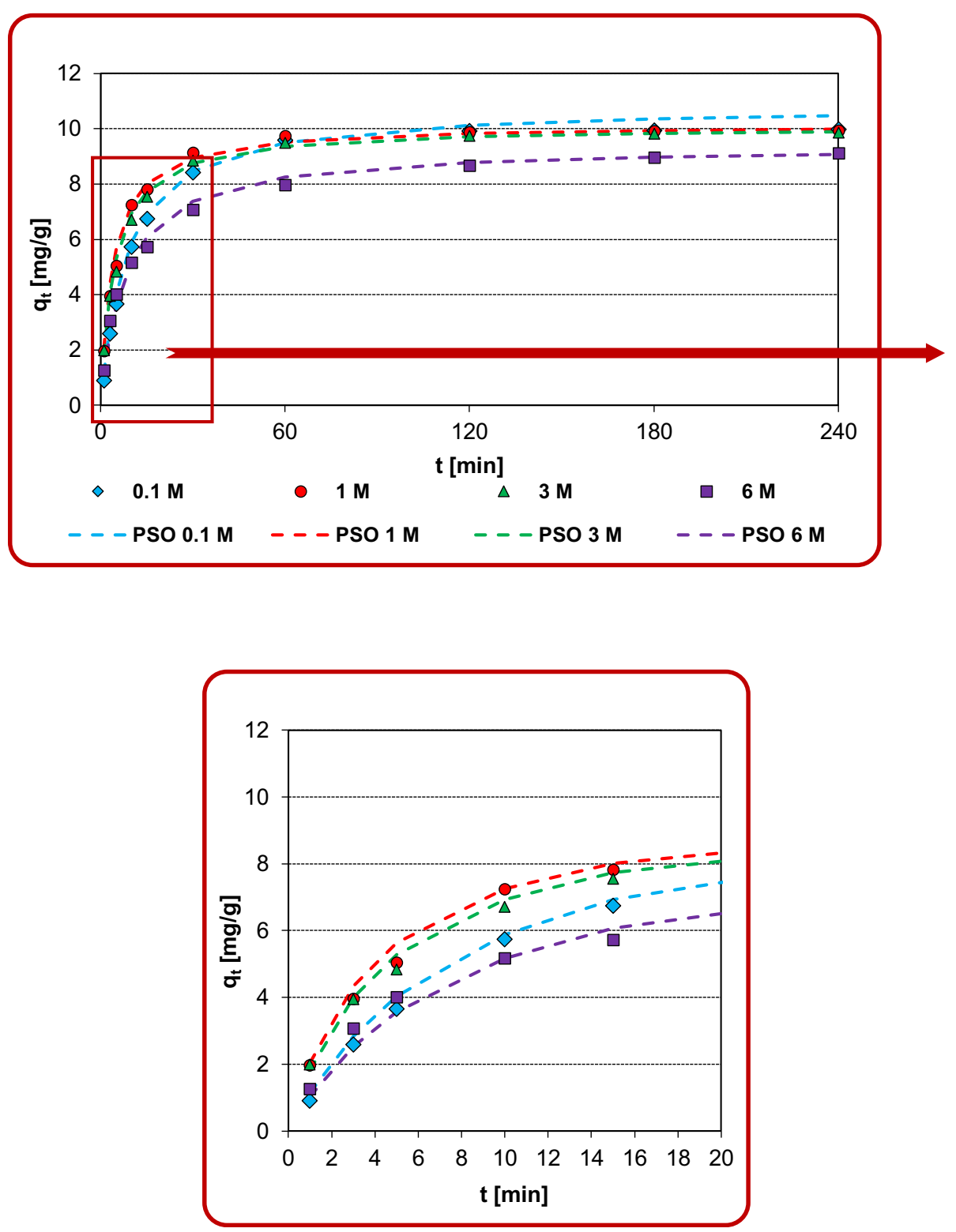
inverse $\left(q_{\mathrm{e}}-q_{\mathrm{t}}\right)$ results that the good fitting of PFO with the experimental point close to the equilibrium could not be observed [55]. Based on the error analysis of PFO and PSO models that means the normalized standard deviation $\Delta q(\%)$ and Chi-square test $\left(\chi^{2}\right)$, these parameters are lower in the case of PSO model, $\Delta q$ was in the range from 4.78 to $12.53 \%$ $(0.1 \mathrm{M} \mathrm{HCl}, \mathrm{PSO})$ and in the range from 43.19 to $57.56 \%(0.1 \mathrm{M} \mathrm{HCl}, \mathrm{PFO})$, whereas the $\chi^{2}$ values were in the range from 0.09 to $0.22(0.1 \mathrm{M} \mathrm{HCl}, \mathrm{PSO})$ and in the range from 13.01 to 48.18 ( $0.1 \mathrm{M} \mathrm{HCl}, \mathrm{PFO})$. Thus, it can be concluded that the $\mathrm{Cu}$ (II) ions sorption on Lewatit MonoPlus TP 220 follows the pseudo-secondorder kinetics. A similar conclusion was also obtained by other researchers who applied different types of sorbents for $\mathrm{Cu}$ (II) removal, e.g. Dada et al. [57] who examined sorption of $\mathrm{Cu}$ (II) onto a novel manganese nano-adsorbent, Faghihian et al. [58] who examined sorption of $\mathrm{Cu}$ (II) onto silica aerogel modified with amino propyl triethoxysilane, Samadi et al. [59] who examined sorption of $\mathrm{Cu}$ (II) onto the chelating resins CSMA-M, CSMA-MO and CSMA$\mathrm{MB}, \mathrm{Cho}$ et al. [60] who examined a novel chitosan/clay/magnetite composite for adsorption of
$\mathrm{Cu}(\mathrm{II})$ and $\mathrm{As}(\mathrm{V})$ ions, Ngah et al. [61] who examined sorption of $\mathrm{Cu}(\mathrm{II})$ ions by three types of chitosanzeolite composites, etc.

\section{Attenuated total reflectance Fourier transform infrared spectroscopy (ATR-FTIR) analysis for Lewatit MonoPlus TP 220 applied for copper(II) sorption}

ATR-FTIR spectra of Lewatit MonoPlus TP 220 before and after copper(II) sorption were recorded to confirm the presence of functional groups of ion exchange resin and to provide some information about $\mathrm{Cu}$ (II) sorption mechanism. The spectra of nonloaded Lewatit MonoPlus TP 220 and after $\mathrm{Cu}(\mathrm{II})$ sorption process (loaded ion exchange resin) are presented in Fig. 9.

From the presented ATR-FT-IR spectra, the peaks related to the resin matrix and their functional groups can be distinguished. As was observed in the higherfrequency region at $3350-3450 \mathrm{~cm}^{-1}$, the broad and intense peak was assigned to the stretching vibrations of the -OH group (maximum of peak can be found at $3346.1 \mathrm{~cm}^{-1}$ (\% $\mathrm{T}$ 88.59)-before sorption and at

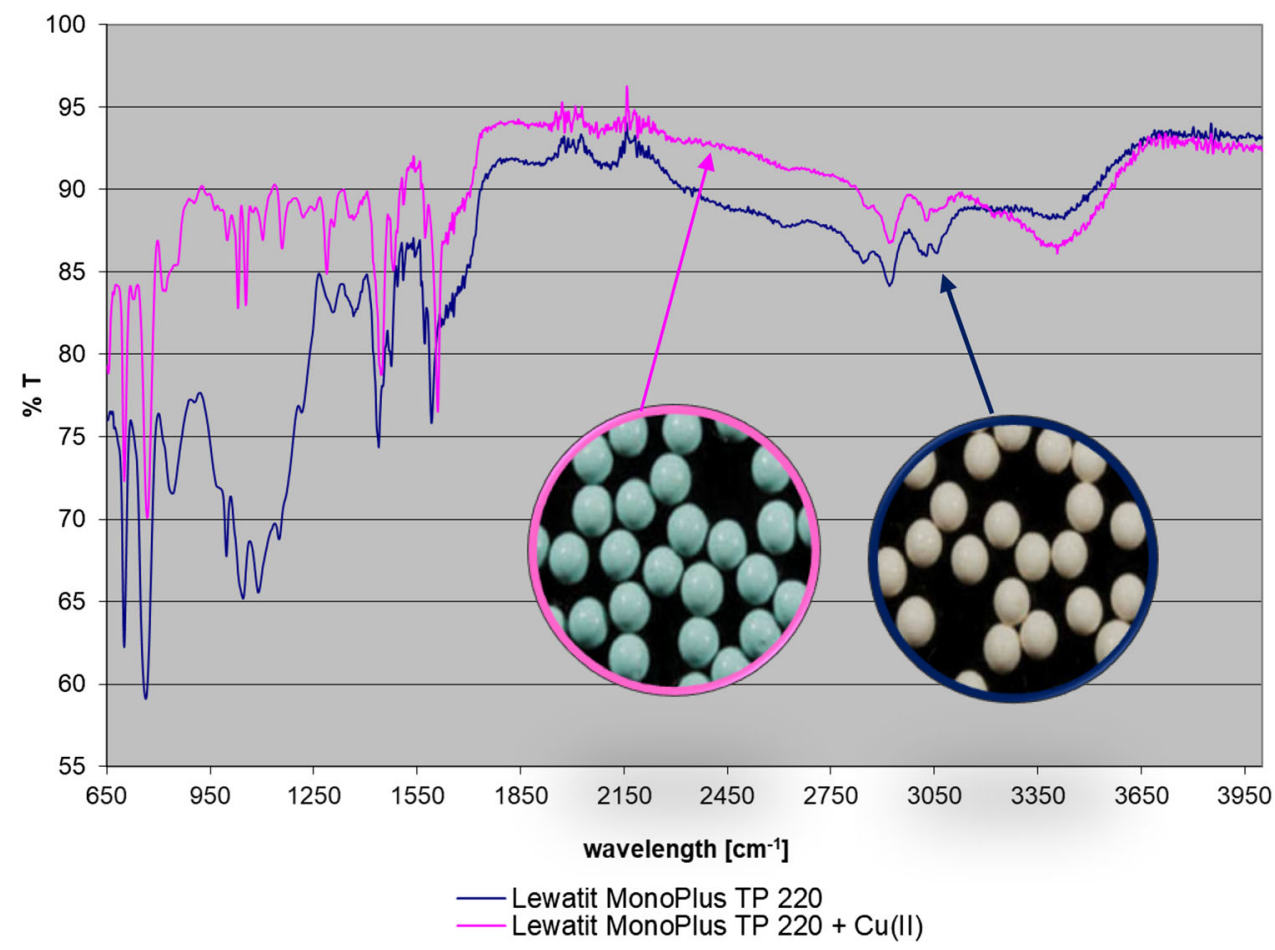

Figure 9 Attenuated total reflectance Fourier transform infrared (ATR-FTIR) spectra for Lewatit MonoPlus TP 220 and after the Cu(II) sorption process. 
$3353.56 \mathrm{~cm}^{-1}$ (\% $\mathrm{T}$ 87)—after $\mathrm{Cu}(\mathrm{II})$ sorption. Moreover, stretching vibrations of the $\mathrm{N}-\mathrm{H}$ groups, symmetric and asymmetric stretching bonds of $-\mathrm{CH}_{2}$ groups (before sorption- $v_{\mathrm{s}}-\mathrm{CH}_{2} \quad 2840-2850 \mathrm{~cm}^{-1}$, $v_{\text {as }}-\mathrm{CH}_{2} 2905-2930 \mathrm{~cm}^{-1}$, after sorption shifted to the higher-frequency region- $v_{\mathrm{s}}-\mathrm{CH}_{2} \quad 2850-2870 \mathrm{~cm}^{-1}$, $v_{\mathrm{as}}-\mathrm{CH}_{2} 2915-2925 \mathrm{~cm}^{-1}$ ) and the peak related to cross-linked polystyrene (before sorption-at 1585-1595 $\mathrm{cm}^{-1}$ and after sorption$1598-1612 \mathrm{~cm}^{-1}$ ) can be found. Additionally, the peak related to the vibrations of $\mathrm{C}=\mathrm{N}$ of pyridine groups as well as the asymmetric scissoring vibrations of the methylene groups $\delta_{\text {as }}$ at $1425-1455 \mathrm{~cm}^{-1}$ (after sorption at $1438-1450 \mathrm{~cm}^{-1}$ ), adsorption peaks of $\mathrm{C}-\mathrm{H}$ at $750-770 \mathrm{~cm}^{-1}$ (after sorption at $760-770 \mathrm{~cm}^{-1}$ ) and peaks related to the amine groups at $950-1250 \mathrm{~cm}^{-1}$ are present. The spectra showed also stretching vibrations of $\mathrm{C}=\mathrm{C}$ and $\mathrm{C}=\mathrm{N}$ characteristic of the functional groups at the wavelength $1650-1400 \mathrm{~cm}^{-1}$ and the bands from the stretching vibrations of the $\mathrm{C}-\mathrm{N}$ groups in aliphatic and aromatic amines. After copper sorption, a significant drop of some band intensity and their shift to the higher-frequency region were found, particularly in the region $950-1250 \mathrm{~cm}^{-1}, \quad 1400-1500 \mathrm{~cm}^{-1}$, $1550-1650 \mathrm{~cm}^{-1}$ in the case of band corresponding to the stretching vibrations of the $\mathrm{O}-\mathrm{H}$ and $\mathrm{N}-\mathrm{H}$ groups and stretching vibrations of the $\mathrm{C}-\mathrm{N}$ groups present in aromatic and aliphatic amines. Such changes could be due to the coordination bands formation with $\mathrm{Cu}$ (II) ions sorbed on the ion exchanger (coordinating mechanism) [7, 31, 62].

\section{Copper(II) desorption from Lewatit \\ MonoPlus TP 220 and ion exchange resin reuse: batch method}

Three sorption/desorption cycles of $\mathrm{Cu}$ (II) on/from Lewatit MonoPlus TP 220 using the batch method were carried out in order to check the desorption possibilities of $\mathrm{Cu}$ (II) ions from the loaded ion exchanger and its reused possibility. Different eluting agents were applied such as acids: $\mathrm{HNO}_{3}, \mathrm{HCl}$, $\mathrm{H}_{2} \mathrm{SO}_{4}$, base: $\mathrm{NaOH}$ and ammonium hydroxide: $\mathrm{NH}_{4} \mathrm{OH}$ of concentration equal to 1 and $2 \mathrm{M}$. The eluting agents were selected based on the literature data concerning the desorption studies of copper(II) from different sorbents and ion exchangers taking into account its efficiency, types and concentration. (More information can be found in Supplementary
Materials.) The other experimental conditions were following: mass of the sorbent applied for sorption and desorption studies, $m_{j}=0.5 \pm 0.0005 \mathrm{~g}$, volume of the solutions containing $\mathrm{Cu}(\mathrm{II}) / \mathrm{L}(\mathrm{S} 1, \mathrm{~S} 2, \mathrm{~S} 3)$ and volume of the eluting agents applied for desorption (D1, D2, D3) V $=0.05 \mathrm{~L}$, initial concentration of copper $\mathrm{Co}=100 \mathrm{mg} \mathrm{Cu}(\mathrm{II}) / \mathrm{L}$-sorption studies, initial concentration of eluting agents, $\mathrm{Co}=1$ or $2 \mathrm{M}-$ desorption studies, agitation speed, $V_{\text {as }}=180 \mathrm{spm}$, amplitude, $A=8$, time of sorption and desorption, $t=2 \mathrm{~h}$, temperature, $T=$ room temperature. Desorption studies using various types of eluents (Fig. 10) have shown that copper ions can be desorbed with different efficiencies. The use of mineral acids for removal of $\mathrm{Cu}$ (II) ions from the Lewatit MonoPlus TP 220 ion exchanger does not give satisfactory results (the effectiveness of desorption with acids was in the range from $0.34-10.46 \%$ (D1) and increases with the increasing acid concentration, e.g. from $2.96 \%-1 \mathrm{M} \mathrm{HNO}_{3}$ to $9.43 \%-2 \mathrm{M} \mathrm{HNO}_{3}$ or from $4.11 \%-1 \mathrm{M} \mathrm{H}_{2} \mathrm{SO}_{4}$ to $10.53 \%-2 \mathrm{M} \mathrm{H}_{2} \mathrm{SO}_{4}$ (D1)). Slightly better results were obtained using $\mathrm{NaOH}$ solutions $(9.84 \%-1 \mathrm{M} \mathrm{NaOH}, 14.24 \%-2 \mathrm{M}$ $\mathrm{NaOH})$. The most effective eluting agent was $2 \mathrm{M}$ $\mathrm{NH}_{4} \mathrm{OH}$, for which the desorption efficiency was $54.38 \%-1 \mathrm{M} \mathrm{NH}_{4} \mathrm{OH}$ and $76.41 \%-2 \mathrm{M} \mathrm{NH} \mathrm{NH}_{4} \mathrm{OH}$. The obtained percentage desorption efficiency in the first cycle (\%D1) causes that $\mathrm{NaOH}$ and $\mathrm{NH}_{4} \mathrm{OH}$ were selected for the second and third sorption/ desorption studies whose yields are presented in Fig. 10 b. In \%D2 and \%D3, the amount of $\mathrm{Cu}(\mathrm{II})$ remaining on the ion exchanger after the previous step was taken into account, e.g. the amount of $\mathrm{Cu}$ (II) remaining on Lewatit MonoPlus TP 220 in the D1 step was included in \%D2 calculations, whereas in $\% \mathrm{D} 3$ calculations the amount of $\mathrm{Cu}$ (II) remaining on the ion exchanger after D1 and D2 was included. The most appropriate eluting agent for copper(II) desorption from the ion exchange resin under discussion was ammonium hydroxide of $2 \mathrm{M}$ concentrations resulting in $76.92 \%$ of $\mathrm{Cu}(\mathrm{II})$ desorption in the first cycle, $69.5 \%$ in the second and $45.9 \%$ in the third cycle. Despite not quantitative $\mathrm{Cu}$ (II) desorption, the ion exchanger could be reused again in the next cycle and still exhibit good sorption properties. After 3 cycles of sorption-desorption (static method), the ion exchange resin shows high sorption capacity in the 3rd cycle and is still as high as in cycle 1. 
Figure 10 Sorption/ desorption studies of $\mathrm{Cu}(\mathrm{II})$ from Lewatit MonoPlus TP 220 a first cycle of sorption/ desorption (S1/D1) and $\mathbf{b}$ its reuse possibilities - second and third sorption/desorption cycles.

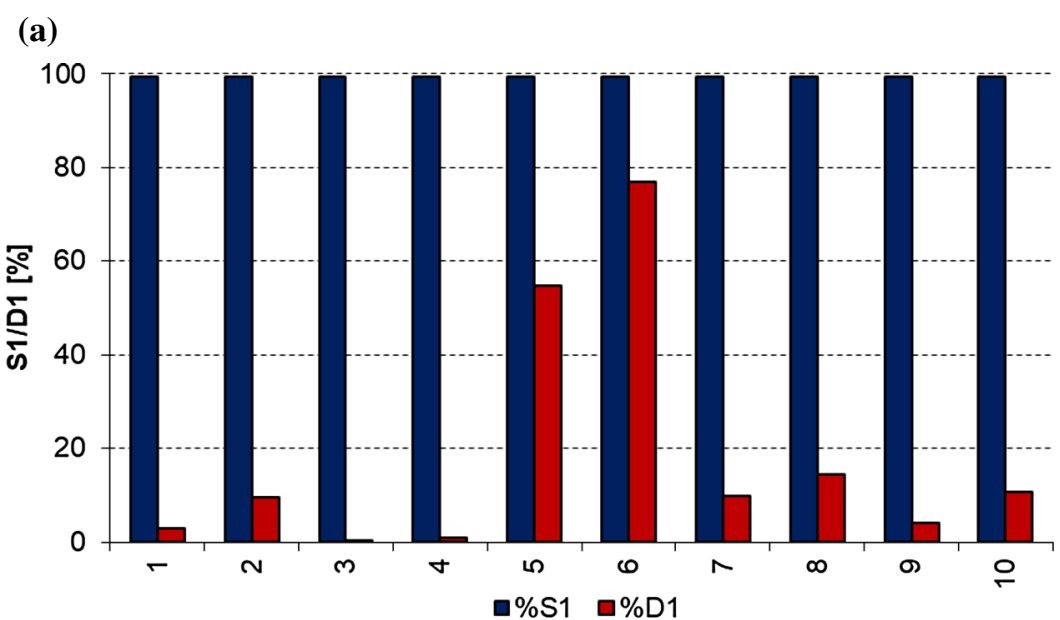

(b)

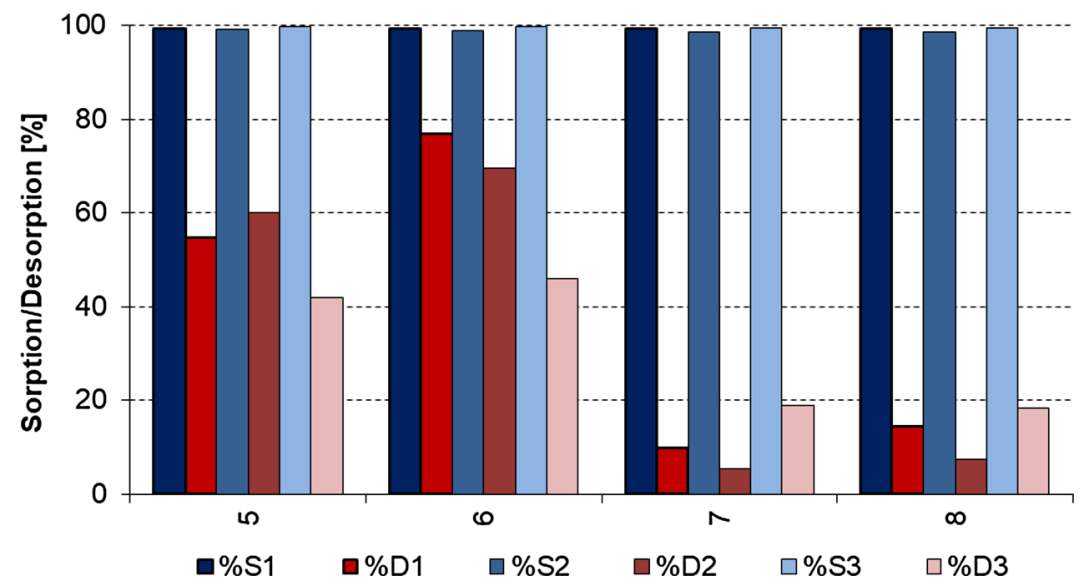

1 - $1 \mathrm{M} \mathrm{HNO}_{3}, 2$ - $2 \mathrm{M} \mathrm{HNO}_{3}, 3$ - $1 \mathrm{M} \mathrm{HCl}, 4$ - $2 \mathrm{M} \mathrm{HCl}, 5$ - $1 \mathrm{M} \mathrm{NH}_{4} \mathrm{OH}, 6$ - $2 \mathrm{M} \mathrm{NH}_{4} \mathrm{OH}$; 7 - $1 \mathrm{M} \mathrm{NaOH}, 8$ - $2 \mathrm{M} \mathrm{NaOH}, 9$ - $1 \mathrm{M} \mathrm{H}_{2} \mathrm{SO}_{4}, 10$ - $2 \mathrm{M} \mathrm{H}_{2} \mathrm{SO}_{4}$
Sorption and desorption test for copper(II) on/from Lewatit MonoPlus TP 220 using the column studies

The goal of the column test is to quantify important parameters which are required to design industrial scale fixed bed adsorption columns. The sorption studies of metals by the column method were carried out from the chloride solutions ((Cu(II), Pd(II), Pt(IV), $\mathrm{Au}(\mathrm{III})$ ) and chloride-nitrate(V) ones (Pd(II), Pt(IV), $\mathrm{Au}(\mathrm{III}))$ in order to obtain the breakthrough curves and calculate sorption parameters. In the case of copper(II) ions after the sorption process (S1), the desorption was performed (D1) and then the next two similar cycles. Some examples of the breakthrough curves are presented in Figs. 11, 12 and 13, whereas the obtained parameters are collected in Table 6.
The breakthrough curve is one of the most important results of a dynamic studies under gravitated flow conditions on a fixed bed-Lewatit MonoPlus TP 220. This curve shows relationships between changes of concentration $\left(C / C_{0}\right)$ versus time and results from different kinetic and thermodynamic effects. As shown in Figs. 11, 12 and 13, the breakthrough curves are characterized by midpoint, steepness and shape. The mentioned curves are not ideal, not symmetrical and not possess typical "S" shape. The sorption capacity, selectivity, the mass transfer of adsorptive molecules into the adsorbent particles, the sorption rate and inlet concentration play a key role during the dynamic sorption process and influence the position and shape of the breakthrough curve considerably. The position and shapes of breakthrough curve contain information about different scales involved in dynamic sorption and 


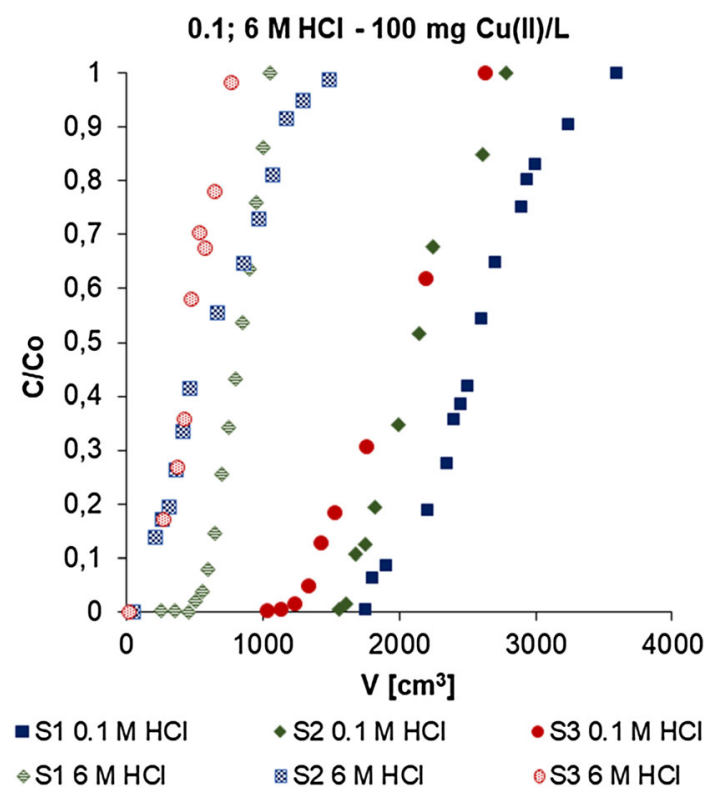

Figure 11 Breakthrough curves obtained during the $\mathrm{Cu}(\mathrm{II})$ sorption from 0.1 and $6 \mathrm{~mol} / \mathrm{L} \mathrm{HCl}$ solutions in the first, second and third cycles, during the metal sorption from $0.1 \mathrm{~mol} / \mathrm{L} \mathrm{HCl}$ solutions on Lewatit MonoPlus TP 220.

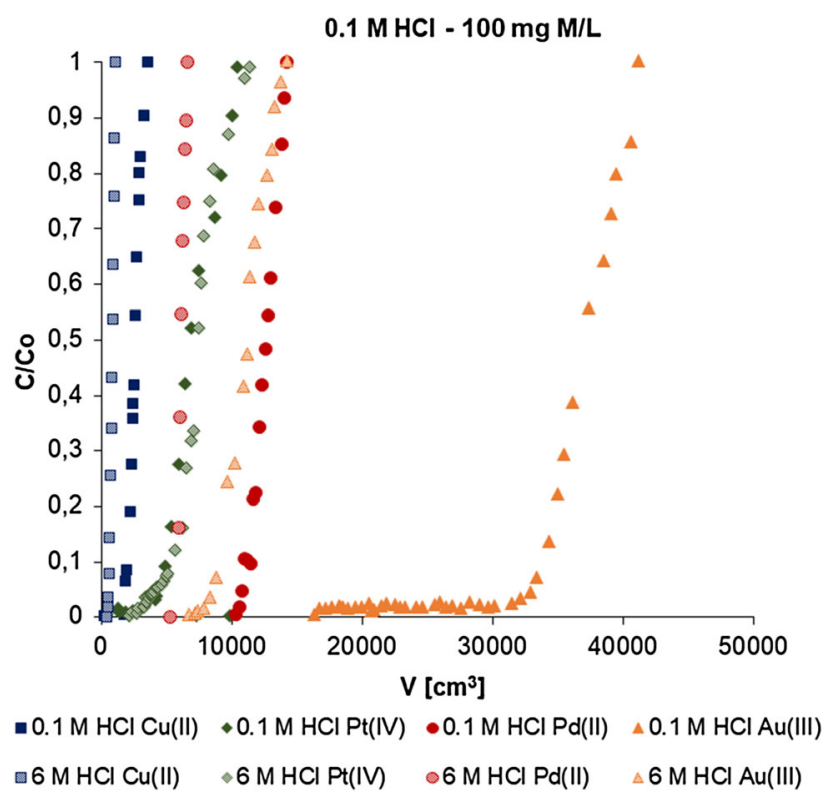

Figure 12 Breakthrough curves obtained during the metal (Cu(II), Pd(II), Pt(IV), Au(III)) sorption from 0.1 and $6 \mathrm{~mol} / \mathrm{L}$ $\mathrm{HCl}$ solutions on Lewatit MonoPlus TP 220.

macro-, meso- and microscopic parameters influences: (a) macroscopic (shape and size of adsorber), (b) mesoscopic (bed porosity and nature of fixed bed, shape and size of particles), (c) microscopic (surface chemistry, textural properties and accessibility).

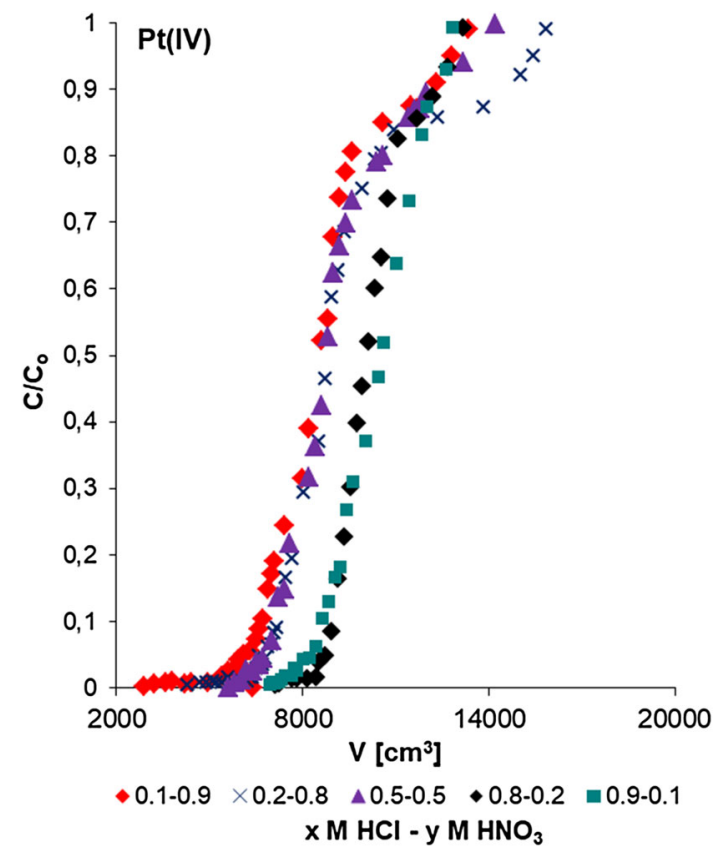

Figure 13 Breakthrough curves obtained during Pt(IV) sorption from $\mathrm{HCl}-\mathrm{HNO}_{3}$ systems on Lewatit MonoPlus TP 220.

The volume of solution collected to the breakthrough point decreases with the $\mathrm{HCl}$ concentration increase, and then Lewatit MonoPlus TP 220 is characterized by a smaller working exchange capacity (presented curves moved to the left side and are closer to point $(0,0))$. The exceptionally large shift of the breakthrough curve is observed in the case of $\mathrm{Au}$ (III) when the concentration of $\mathrm{HCl}$ changes from 0.1 to $1 \mathrm{M}$. In this case the working capacity reduction is $36 \%\left(C_{\mathrm{r}}\right.$ changes from $0.164 \mathrm{~g} / \mathrm{cm}^{3}$ to $\left.0.105 \mathrm{~g} / \mathrm{cm}^{3}\right)$, whereas in the case of $\mathrm{Cu}(\mathrm{II})$ is $2.86 \%, \mathrm{Pd}(\mathrm{II}) 22 \%$ and $\mathrm{Pt}(\mathrm{IV}) 22.2 \%$. The highest sorption capacities are observed in the dilute acidic solution $(0.1 \mathrm{M} \mathrm{HCl})$, and the selectivity series is as follows: $\mathrm{Au}(\mathrm{III})(0.164 \mathrm{~g} /$ $\left.\mathrm{cm}^{3}\right) \gg \mathrm{Pd}(\mathrm{II})\left(0.104 \mathrm{~g} / \mathrm{cm}^{3}\right)>\mathrm{Pt}(\mathrm{IV})\left(0.099 \mathrm{~g} / \mathrm{cm}^{3}\right)-$ $\gg \mathrm{Cu}$ (II) $\left(0.0175 \mathrm{~g} / \mathrm{cm}^{3}\right)$. In the case of $\mathrm{HCl}-\mathrm{HNO}_{3}$ systems, the values of $\mathrm{C}_{\mathrm{r}}$ usually grow with the $\mathrm{HCl}$ concentration increase and $\mathrm{HNO}_{3}$ concentration decrease, e.g. from $0.004 \mathrm{~g} / \mathrm{cm}^{3}(0.1 \mathrm{M} \mathrm{HCl}-0.9 \mathrm{M}$ $\left.\mathrm{HNO}_{3} ; \mathrm{Au}(\mathrm{III})\right)$ to $0.102 \mathrm{~g} / \mathrm{cm}^{3}$ (0.9 M HCl-0.1 M $\left.\mathrm{HNO}_{3} ; \mathrm{Au}(\mathrm{III})\right)$. The sorption capacity has significant impact on the position of the breakthrough curve. By increasing the sorption capacity (see e.g. Fig. 11 and breakthrough curve for $\mathrm{Au}(\mathrm{III})$ ), the breakthrough curve is shifted to longer breakthrough times (curve moved to the right) because more $\mathrm{Au}(\mathrm{III})$ ions will be held back by Lewatit MonoPlus TP 220. On the other 
Table 6 Column tests parameters using Lewatit MonoPlus TP 220

\begin{tabular}{|c|c|c|c|c|c|c|c|c|c|c|}
\hline \multirow[t]{3}{*}{ System } & \multicolumn{4}{|c|}{$C_{\mathrm{r}}\left(\mathrm{g} / \mathrm{cm}^{3}\right)$} & \multicolumn{3}{|l|}{$D_{\mathrm{m}}$} & \multicolumn{3}{|l|}{$D_{\mathrm{v}}$} \\
\hline & \multicolumn{10}{|l|}{$\mathrm{Cu}(\mathrm{II})$} \\
\hline & $\mathrm{S} 1$ & $\mathrm{~S} 2$ & S & & $\mathrm{S} 1$ & $\mathrm{~S} 2$ & S3 & $\mathrm{S} 1$ & $\mathrm{~S} 2$ & S3 \\
\hline $0.1 \mathrm{M} \mathrm{HCl}$ & 0.0175 & 0.0 & & & 827.1 & 693.6 & 652.6 & 257.8 & 216.2 & 203.4 \\
\hline $1 \mathrm{M} \mathrm{HCl}$ & 0.0170 & 0.0 & & & 768.0 & 659.0 & 578.8 & 239.4 & 205.4 & 180.4 \\
\hline $3 \mathrm{M} \mathrm{HCl}$ & 0.0130 & 0.0 & & & 652.6 & 540.3 & 431.2 & 203.4 & 168.4 & 134.4 \\
\hline $6 \mathrm{M} \mathrm{HCl}$ & 0.0045 & 0.0 & & & 269.2 & 200.2 & 158.5 & 83.9 & 62.4 & 49.4 \\
\hline \multirow{3}{*}{\multicolumn{2}{|c|}{ System }} & \multicolumn{3}{|c|}{$C_{\mathrm{r}}\left(\mathrm{g} / \mathrm{cm}^{3}\right)$} & \multicolumn{3}{|l|}{$D_{\mathrm{m}}$} & \multicolumn{3}{|l|}{$D_{\mathrm{v}}$} \\
\hline & & \multicolumn{3}{|l|}{$\mathrm{S} 1$} & \multicolumn{3}{|l|}{ S1 } & \multicolumn{3}{|l|}{$\mathrm{S} 1$} \\
\hline & & $\operatorname{Pd}(\mathrm{II})$ & $\mathrm{Pt}(\mathrm{IV})$ & $\mathrm{Au}(\mathrm{III})$ & $\operatorname{Pd}(\mathrm{II})$ & $\operatorname{Pt}(\mathrm{IV})$ & $\mathrm{Au}(\mathrm{III})$ & $\operatorname{Pd}(\mathrm{II})$ & $\mathrm{Pt}(\mathrm{IV})$ & $\mathrm{Au}(\mathrm{III})$ \\
\hline \multicolumn{2}{|l|}{$0.1 \mathrm{M} \mathrm{HCl}$} & 0.104 & 0.099 & 0.164 & 4056.5 & 4560.8 & 1862.7 & 1264.4 & 1421.6 & 3697.6 \\
\hline \multicolumn{2}{|l|}{$1 \mathrm{M} \mathrm{HCl}$} & 0.080 & 0.077 & 0.105 & 3332.1 & 3896.1 & 5949.6 & 1038.6 & 1014.4 & 1854.5 \\
\hline \multicolumn{2}{|l|}{$3 \mathrm{M} \mathrm{HCl}$} & 0.076 & 0.065 & 0.079 & 3032.1 & 3078.3 & 4071.9 & 945.1 & 959.5 & 1269.2 \\
\hline \multicolumn{2}{|l|}{$6 \mathrm{M} \mathrm{HCl}$} & 0.053 & 0.022 & 0.068 & 1923.6 & 2407.4 & 3632.7 & 599.6 & 750.4 & 1132.3 \\
\hline \multicolumn{2}{|c|}{$0.1 \mathrm{M} \mathrm{HCl}-0.9 \mathrm{M} \mathrm{HNO}_{3}$} & 0.070 & 0.029 & 0.004 & 3335.3 & 2735.3 & 736.0 & 1039.6 & 852.6 & 229.4 \\
\hline \multicolumn{2}{|c|}{$0.2 \mathrm{M} \mathrm{HCl}-0.8 \mathrm{M} \mathrm{HNO}_{3}$} & 0.069 & 0.043 & 0.042 & 3328.2 & 2823.9 & 6793.1 & 1037.4 & 880.2 & 2117.4 \\
\hline \multicolumn{2}{|c|}{$0.5 \mathrm{M} \mathrm{HCl}-0.5 \mathrm{M} \mathrm{HNO}_{3}$} & 0.068 & 0.056 & 0.044 & 2943.2 & 2804.6 & 4890.6 & 917.4 & 874.2 & 1524.4 \\
\hline \multicolumn{2}{|c|}{$0.8 \mathrm{M} \mathrm{HCl}-0.2 \mathrm{M} \mathrm{HNO}_{3}$} & 0.075 & 0.072 & 0.044 & 3013.2 & 3237.7 & 5002.9 & 939.2 & 1009.2 & 1559.4 \\
\hline \multicolumn{2}{|c|}{$0.9 \mathrm{M} \mathrm{HCl}-0.1 \mathrm{M} \mathrm{HNO}_{3}$} & 0.079 & 0.070 & 0.102 & 2992.6 & 332.4 & 3731.8 & 932.8 & 1057.4 & 1163.2 \\
\hline
\end{tabular}

hand, the observed steep shape of breakthrough curve indicates that sorption kinetics is fast (spontaneous breakthrough occurs are not observed) (for faster kinetics the breakthrough curve becomes steeper). Short local equilibrium times are formed due to fast mass transfer results in smaller enlargement of the concentration front (compensation by other effects can be also observed). Additionally the asymmetric shape of breakthrough curve can be caused by the thermodynamic effect, by axial dispersion as well as heterogeneity of adsorbents [63, 64].

The bed and weight distribution coefficients in the chloride solutions decrease significantly with the $\mathrm{HCl}$ concentration increase as a results of competitive effect, whereas in the chloride-nitrate(V) solutions these parameters do not show clear trend in the changes with those of $\mathrm{HCl}$ and $\mathrm{HNO}_{3}$ concentrations.

After three cycles of sorption-desorption, the S1-D1S2-D2-S3-D3 (Cu(II) sorption by Lewatit MonoPlus TP 220 from $0.1,1,3$ and $6 \mathrm{M} \mathrm{HCl}$ ) was observed that the working ion exchange capacities, the weight and bed distribution coefficients decrease in the second and third cycles, e.g. $C_{\mathrm{r}}\left(\mathrm{g} / \mathrm{cm}^{3}\right)$ obtained during the $\mathrm{Cu}$ (II) sorption from $0.1 \mathrm{M} \mathrm{HCl}$ solutions was 0.0175 (S1), 0.0161 (S2) and 0.0133 (S3), respectively. The desorption curves $\left(\mathrm{Cu}\right.$ (II) desorption using $\left.2 \mathrm{M} \mathrm{NH}_{4} \mathrm{OH}\right)$ in all cases are characterized by a high desorption peak at the beginning (sharp increase in $\mathrm{Cu}$ (II) ions in the solutions after desorption), then the concentration of $\mathrm{Cu}$ (II) in solution after desorption slowly decreases, and tailing of the peak is observed. The maximum of peaks is observed after using 25-35 $\mathrm{ml}$ of desorbing solutions in all cases ( $\mathrm{Cu}$ (II) sorption from $0.1,1,3$, and $6 \mathrm{M} \mathrm{HCl}$ ), and the height of the peaks decreases with the $\mathrm{HCl}$ concentration increase, e.g. the $\mathrm{Cu}$ (II) concentration decreases from $8136.4 \mathrm{mg} / \mathrm{L}$ (sorption from $0.1 \mathrm{M} \mathrm{HCl}$ ) through $7459.0 \mathrm{mg} / \mathrm{L}$ (sorption from $1 \mathrm{M} \mathrm{HCl}), 6222.7 \mathrm{mg} / \mathrm{L}$ (sorption from $3 \mathrm{M} \mathrm{HCl}$ ) to $1033.9 \mathrm{mg} / \mathrm{L}$ (sorption from $6 \mathrm{M} \mathrm{HCl})$. Passing through the column even about $3 \mathrm{~L}$ (2985 to $3335 \mathrm{ml}, 2555-3775 \mathrm{ml}$ ) or about $2 \mathrm{~L}$ (1660-2280 ml) of the desorbing solution $\left(2 \mathrm{M} \mathrm{NH}_{4} \mathrm{OH}\right)$ due to the tailing of the peak gives in the solution a trace concentration of $\mathrm{Cu}$ (II) ions of $0.39-0.9 \mathrm{mg} / \mathrm{L}$ (desorption cycle $1, \mathrm{D} 1), 0.08-1.4 \mathrm{mg} / \mathrm{L}$ (desorption cycle 2 , D2) or $1.65-1.96 \mathrm{mg} / \mathrm{L}$ (desorption cycle 3, D3). The desorption process could be observed visually because the solution after the desorption process changed its colour from colourless to heavily navy blue (desorption peak achieved the maximum, $\mathrm{Cu}$ (II) concentration in the eluate was the highest), and then the colour of the eluate decreased its intensity (increasingly paler blue), until colourless (trace concentration of $\mathrm{Cu}(\mathrm{II})$ ). As the 
results show, Lewatit MonoPlus TP 220 is characterized very good sorption properties for noble metals, especially for $\mathrm{Au}(\mathrm{III})$ and among base metals, e.g. $\mathrm{Cu}$ (II), $\mathrm{Co}$ (II), $\mathrm{Zn}$ (II), $\mathrm{Ni}$ (II) good sorption properties for $\mathrm{Cu}$ (II). Lewatit MonoPlus TP 220 possesses still high sorption ability for $\mathrm{Cu}$ (II) even after 3 cycles of sorption-desorption [reduction of capacity is small and equal to $8 \%\left(C_{\mathrm{w}}\right.$ from $\mathrm{S} 1$ to $\left.\mathrm{S} 2\right)$ and $17.4 \%\left(C_{\mathrm{w}}\right.$ from $\mathrm{S} 2$ to S3) $(0.1 \mathrm{M} \mathrm{HCl})]$. In the case of sorption from $1 \mathrm{M}$ $\mathrm{HCl}$ solutions $C_{\mathrm{r}}$ capacity reduction from $\mathrm{S} 1$ to $\mathrm{S} 2$ and from S2 to S3 was $18.2 \%$ and $27.3 \%$, whereas from $3 \mathrm{M}$ $\mathrm{HCl}$ solutions it was $16.2 \%$ and $12.8 \%$. Only in the more concentrated solutions of $\mathrm{HCl}(6 \mathrm{M} \mathrm{HCl})$ the $C_{\mathrm{r}}$ reduction was very high and equal to $88.9 \%$ and $60 \%$. As found by Yahorava et al. [65] during the Co(II) and $\mathrm{Cu}$ (II) sorption on the Fiban sorbents, Fiban AK22(3) lost its capacity within only 10 cycles of adsorption and elution, whereas Fiban X-1 retained capacity over 20 cycles of adsorption and desorption and in this case the desorption from Fiban X-1 was quantitative. Desorption efficiency of $\mathrm{Cu}$ (II) from SCAM-1 (cellulose sorbent, surface area $=189.12 \mathrm{~m}^{2} / \mathrm{g}$ ) was $62.1-100 \%$ using a $\mathrm{HCl}$ or $\mathrm{NaOH}$ solution, whereas using $2 \mathrm{M} \mathrm{HCl}$ almost $100 \%$ of the $\mathrm{Cu}$ (II) was removed. The sorbent SCAM-1 is a promising adsorbent for copper removal from copper-bearing wastewaters because after 10 replications of adsorption and desorption cycles adsorption capacity is still on a similar level whereas after 20 or 30 cycles the capacity values reduction was only $2.6 \%$ and $7.2 \%$ [66].

\section{Conclusions}

Eight sorbents were applied for copper(II) ions sorption from the chloride and chloride-nitrate(V) solutions. Sorption studies indicate that Lewatit MonoPlus TP 220 shows the highest affinity for $\mathrm{Cu}$ (II) ions compared to the other ion exchangers under discussion in all examined $\mathrm{HCl}$ and $\mathrm{HCl}-\mathrm{HNO}_{3}$ systems and was selected for future studies. Moreover, the kinetic studies show that the amount of $\mathrm{Cu}$ (II) sorbed on Lewatit MonoPlus TP 220 depends on the time of agitation and the ion exchanger is characterized by moderately fast kinetics, the time required to reach equilibrium was higher than $120 \mathrm{~min}(\mathrm{HCl}$ systems) and higher than $60 \mathrm{~min}(\mathrm{HCl}-$ $\mathrm{HNO}_{3}$ systems). Additionally, the sorption of $\mathrm{Cu}$ (II) on Lewatit MonoPlus TP 220 could be described by the pseudo-second-order kinetic equation $(\Delta q=$ $\left.4.78-12.53 \%, \chi^{2}=0.09-0.22\right)$. High sorption ability for
copper(II) was also confirmed by the equilibrium studies [sorption capacity of Lewatit MonoPlus TP 220 towards $\mathrm{Cu}$ (II) $=230.2 \mathrm{mg} / \mathrm{g}$ and was much higher for the other sorbents (sorption capacities from 140 to $117.8 \mathrm{mg} / \mathrm{g}$ )]. The maximum sorption capacity calculated from the Langmuir model $\left(Q_{0}=221.43 \mathrm{mg} / \mathrm{g}\right)$ was close to the experimental one indicating favourable sorption and good fitting of experimental results. The FTIR studies confirmed the coordinated binding mechanism during the $\mathrm{Cu}$ (II) sorption on Lewatit MonoPlus TP 220 and on all examined sorbents is anion exchange, coordinate, electrostatic interaction or mixed. Selectivity of ion exchange resins towards copper(II) ions during the simultaneous sorption of $\mathrm{Pd}(\mathrm{II})$ and $\mathrm{Cu}$ (II) ions from the acidic solutions increases in the presence of Pd(II) increase. Lewatit MonoPlus TP 220 shows also a high sorption ability for noble metals from single and three-component solutions, particularly for $\mathrm{Au}(\mathrm{III})$ - column test). Desorption of $\mathrm{Cu}$ (II) from Lewatit MonoPlus TP 220 was the highest using $2 \mathrm{M}$ $\mathrm{NH}_{4} \mathrm{OH}$ (it was not quantitative), but the additional sorption-desorption tests show that this ion exchanger is a promising candidate for $\mathrm{Cu}(\mathrm{II})$ removal from the model and real acidic streams.

\section{Compliance with ethical standards}

Conflict of interest The authors declare that they have no known competing financial interests or personal relationships that could have appeared to influence the work reported in this paper.

Open Access This article is licensed under a Creative Commons Attribution 4.0 International License, which permits use, sharing, adaptation, distribution and reproduction in any medium or format, as long as you give appropriate credit to the original author(s) and the source, provide a link to the Creative Commons licence, and indicate if changes were made. The images or other third party material in this article are included in the article's Creative Commons licence, unless indicated otherwise in a credit line to the material. If material is not included in the article's Creative Commons licence and your intended use is not permitted by statutory regulation or exceeds the permitted use, you will need to obtain permission directly from the copyright holder. To view a copy of this licence, visit $h$ ttp://creativecommons.org/licenses/by/4.0/. 
Electronic supplementary material: The online version of this article (https://doi.org/10.1007/s108 53-020-04982-z) contains supplementary material, which is available to authorized users.

\section{References}

[1] Beatty R (2001) The element copper. Marshall Cavendish, New York

[2] Modrogan C, Miron AR, Orbulet OD, Costache C, Apostol $G$ (2015) Ion exchange process on weak acid resins for wastewater containing copper ions treatment. Environ Eng Manag J. 14:449-454

[3] Davis JR (ed) (2001) Copper and copper alloys. ASM International, Cleveland

[4] Piontek M, Fedyczak Z, Łuszczyńska K, Lechów H (2014) Toksyczność miedzi, cynku oraz kadmu, rtęci i ołowiu dla człowieka, kręgowców i organizmów wodnych. Inżynieria środowiska 35:70-83 (in Polish)

[5] Günter J, Kundig KJA (1999) Copper: its trade, manufacture, use, and environmental status. ASM International, Cleveland

[6] Anyadike N (2002) Copper: a material for the new millennium. Woodhead Publishing Ltd., Cambridge

[7] Kołodyńska D, Sofińska-Chmiel W, Mendyk E, Hubicki Z (2014) Dowex M4195 and Lewatit MonoPlus TP220 in heavy metal ions removal from acidic streams. Sep Sci Technol 49:2003-2015. https://doi.org/10.1080/01496395.2 014.908920

[8] Giannopoulou I, Panias D (2007) Copper and nickel recovery from acidic polymetallic aqueous solutions. Min Eng 20:753-760. https://doi.org/10.1016/j.mineng.2007.02.009

[9] Nguyen NV, Lee J, Jha MK, Yoo K, Jeong J (2009) Copper recovery from low concentration waste solutions using Dowex G-26 resin. Hydrometallurgy 97:237-242. https://d oi.org/10.1016/j.hydromet.2009.03.003

[10] Al-Saydeh SAA, El-Naas MH, Zaidi SJ (2017) Copper removal from industrial wastewater: a comprehensive review. J Ind Eng Chem 56:35-44. https://doi.org/10.1016/j. jiec.2017.07.026

[11] Sharma S, Bhattacharya A (2017) Drinking water contamination and treatment techniques. Appl Water Sci 7:1043-1067. https://doi.org/10.1007/s13201-016-0455-7

[12] Crini G, Lichtfouse E (2019) Advantages and disadvantages of techniques used for wastewater treatment. Environ Chem Lett 17(1):145-155. https://doi.org/10.1007/s10311-018-07 85-9

[13] Kanamarlapudi SLRK, Chintalpudi VK, Muddada S (2018) Application of biosorption for removal of heavy metals from wastewater. InTech 4:69-116. https://doi.org/10.5772/intech open.77315

[14] Fu F, Wang Q (2011) Removal of heavy metal ions from wastewaters: a review. J Environ Manag 92(3):407-418. h ttps://doi.org/10.1016/j.jenvman.2010.11.011

[15] Fonseca Couto C, Lange LC, Santos Amaral MC (2018) A critical review on membrane separation processes applied to remove pharmaceutically active compounds from water and wastewater. J Water Process Eng 26:156-175. https://doi. org/10.1016/j.jwpe.2018.10.010

[16] Rubio J, Souza ML, Smith RW (2002) Overview of flotation as a wastewater treatment technique. Miner Eng 15:139-155. https://doi.org/10.1016/s0892-6875(01)00216-3

[17] Ingle AP, Paralikar P, Shende S, Gupta I, Biswas JK, da Silva Martins LH, Rai M (2018) Copper in medicine: Perspectives and toxicity, chapter 4. In: Rai M, Ingle AP, Medici S (eds) Biomedical applications of metals. Springer, Cham, pp 95-112. https://doi.org/10.1007/978-3-319-74814-6_4

[18] Senczuk W (2005) Toksykologia współczesna. PZWL, Warszawa (in Polish)

[19] Yruela I (2009) Copper in plants: acquisition, transport and interactions. Funct Plant Biol 36:409-430. https://doi.org/10. 1590/s1677-04202005000100012

[20] 7Demayo A, Taylor MC, Taylor KW, Wiersma GB (1982) Effects of copper on humans, laboratory and farm animals, terrestrial plants, and aquatic life. J Crit Rev Environ Control 12(3):183-255. https://doi.org/10.1080/10643388209381697

[21] Rao CRM, Reddi GS (2000) Platinum group metals (PGM); occurrence, use and recent trends in their determination. Trends Anal Chem 19:565-586. https://doi.org/10.1016/S0 165-9936(00)00031-5

[22] Godlewska-Żyłkiewicz B (2004) Preconcentration and separation procedures for the spectrochemical determination of platinum and palladium. Microchim Acta 147:189-210. h ttps://doi.org/10.1016/S0165-9936(00)00031-5

[23] Gaita R, AlBazi SJ (1995) An ion-exchange method for selective separation of palladium, platinum and rhodium from solutions obtained by leaching automotive catalytic converters. Talanta 42:249-255. https://doi.org/10.1016/003 9-9140(94)00246-O

[24] Xing WD, Sohn SH, Lee MS (2020) A review on the recovery of noble metals from anode slimes. Mineral Process Extr Metall Rev 41(2):130-145. https://doi.org/10.1080/08 827508.2019 .1575211

[25] Wang W, Xu Z, Huang ST, Yang LM, Cai LL, Ji ZG, Li Y (2014) Characteristics research and selective leaching of anode slime with high content of copper and stannum. Adv Mater Res 1010-1012:1594-1597. https://doi.org/10.4028/ www.scientific.net/AMR.1010-1012.1594 
[26] Harland CE (1994) Ion exchange: theory and practice. Royal Society of Chemistry, Cambridge

[27] Ciesielczyk F, Bartczak P, Klapiszewski Ł, Jesionowski T (2017) Treatment of model and galvanic waste solutions of copper(II) ions using a lignin/inorganic oxide hybrid as an effective sorbent. J Hazard Mater 328:150-159. https://doi. org/10.1016/j.jhazmat.2017.01.009

[28] Samadi N, Ansari R, Khoavirdilo B (2017) Removal of Copper ions from aqueous solutions using polymer derivations of poly (styrene-alt-maleic anhydride). Egyptian J. Petrol. 26:375-389. https://doi.org/10.1016/j.ejpe.2016.05. 010

[29] Balistrieri LS, Murray JW (1981) The surface chemistry of goethite $(\alpha-\mathrm{FeOOH})$ in major ion seawater. Am J Sci 281:788-806. https://doi.org/10.2475/ajs.281.6.788

[30] Fiol N, Villaescusa I (2009) Determination of sorbent point zero charge: usefulness in sorption studies. Environ Chem Lett 7:79-84. https://doi.org/10.1007/s10311-008-0139-0

[31] Wołowicz A, Hubicki Z (2012) The use of the chelating resin of a new generation Lewatit MonoPlus TP-220 with the bispicolylamine functional groups in the removal of selected metal ions from acidic solutions. Chem Eng J 197:493-508. https://doi.org/10.1016/j.cej.2012.05.047

[32] Wołowicz A, Hubicki Z (2014) Polyacrylate ion exchangers in sorption of noble and base metal ions from single and tertiary component solutions. Solv Extr Ion Exch 32:189-205. https://doi.org/10.1080/07366299.2013.838494

[33] Wołowicz A, Hubicki Z (2016) Sorption behavior of Dowex PSR-2 and Dowex PSR-3 resins of different structures for metal(II) removal. Solvent Extr Ion Exch 34:375-397. http s://doi.org/10.1080/07366299.2016.1187983

[34] Wołowicz A, Hubicki Z (2016) Carbon-based microporous adsorber Lewatit AF 5 applicability in metal ion recovery. Micropor Mesopor Mater 224:400-414. https://doi.org/10. 1016/j.micromeso.2015.12.051

[35] Edebali S, Pehlivan E (2016) Evaluation of chelate and cation exchange resins to remove copper ions. Powder Technol 301:520-525. https://doi.org/10.1016/j.powtec.201 6.06 .011

[36] Hubicki Z, Kołodyńska D (2012) Selective removal of heavy metal ions from waters and waste waters using ion exchange methods, Chapter 8. In: Kilislioğlu A (ed) Ion exchange technologies. In Tech, London, pp 193-240

[37] Kołodyńska D (2009) Chelating ion exchange resins in removal of heavy metal ions from waters and wastewaters in presence of a complexing agent. Przem Chem 88:182-189 (in Polish)

[38] Sengupta AK, Zhu Y, Hauze D (1991) Metal(II) in binding onto chelating exchangers with nitrogen donor atoms: some new observations and related implications. Environ Sci Technol 25:481-488. https://doi.org/10.1021/es00015a016

[39] Zonga L, Liua F, Chena D, Zhanga X, Linga Ch, Lia A (2018) A novel pyridine based polymer for highly efficient separation of nickel from high-acidity and high-concentration cobalt solutions. Chem Eng J 334:995-1005. https://doi. org/10.1016/j.cej.2017.10.127

[40] Chatterjee PK, SenGupta AK (2011) Interference-free detection of trace copper in the presence of EDTA and other metals using two complementary chelating polymers. Colloids Surf A Physicochem Eng Aspects 384:432-441. http s://doi.org/10.1016/j.colsurfa.2011.04.031

[41] Langmuir I (1918) The adsorption of gases on plane surfaces of glass, mica and platinum. J Am Chem Soc 40:1361-1368

[42] Freundlich HMF (1906) Over the adsorption in solution. J Phys Chem 57:385-470

[43] Hamidi A, Arsalane S, Halim M (2012) Kinetics and isotherm studies of copper removal by brushite calcium phosphate: linear and non-linear regression comparison. E-J Chem 9:1532-1542

[44] Jayakumar R, Rajasimman M, Karthikeyan C (2015) Optimization, equilibrium, kinetic, thermodynamic and desorption studies on the sorption of $\mathrm{Cu}(\mathrm{II})$ from an aqueous solution using marine green algae: Halimeda gracilis. Ecotoxicol Environ Saf 21:199-210. https://doi.org/10.1016/j.ec oenv.2015.03.040

[45] Burakov AE, Galunin EV, Burakova IV, Kucherova AE, Agarwal S, Tkachev AG, Gupta VK (2018) Adsorption of heavy metals on conventional and nanostructured materials for wastewater treatment purposes: a review. Ecotoxicol Environ Saf 148:702-712. https://doi.org/10.1016/j.ecoenv. 2017.11.034

[46] Ihsanullah, Abbas A, Al-Amer AM, Laoui T, Al-Marri MJ, Nasser MS, Khraisheh M, Atieh MA (2016) Heavy metal removal from aqueous solution by advanced carbon nanotubes: critical review of adsorption applications. Sep Purif Technol 157:141-161. https://doi.org/10.1016/j.seppur.2015. 11.039

[47] Wołowicz A, Hubicki Z (2012) Ion exchange recovery of palladium(II) from acidic solutions using monodisperse Lewatit SR-7. Ind Eng Chem Res 51:16688-16696. https://d oi.org/10.1021/ie302304c

[48] Wołowicz A, Hubicki Z (2014) Adsorption characteristics of noble metals on the strongly basic anion exchanger Purolite A 400 TL. J Mater Sci 49:6191-6202. https://doi.org/10. 1007/s10853-014-8333-x

[49] Wołowicz A, Hubicki Z (2012) Applicability of new acrylic, weakly basic anion exchanger Purolite A-830 of very high capacity in removal of palladium(II) chlorocomplexes. Ind 
Eng Chem Res 51:6191-6202. https://doi.org/10.1021/ie 202859n

[50] Kononova ON, Karplakova NS, Duba EV (2015) Sorption recovery of platinum(II, IV) in presence of copper(II) and zinc(II) from chloride solutions. J Serb Chem Soc 80:1149-1160. https://doi.org/10.2298/JSC141217018K

[51] Kononova ON, Kuznetsova MA, Melnikov AM, Karplakova NS, Kononov YS (2014) Sorption recovery of copper(II) and zinc(II) from aqueous chloride solutions. J Serb Chem Soc 79:1037-1049. https://doi.org/10.2298/JSC130911033K

[52] Zhao H, Chang J, Boika A, Bard AJ (2013) Electrochemistry of high concentration copper chloride complexes. Anal Chem 85:7696-7703. https://doi.org/10.1021/ac4016769

[53] Kononova ON, Duba EV, Shnaider NI, Pozdnyakov IA (2017) Ion exchange extraction of platinum(IV) and palladium(II) from hydrochloric acid solutions. Russ J Appl Chem 90:1239-1245. https://doi.org/10.1134/S107042721 7080080

[54] Dada OA, Adekola FA, Odebunmi EO (2017) A novel zerovalent manganese for removal of copper ions: synthesis, characterization and adsorption studies. Appl Water Sci 7:1409-1427. https://doi.org/10.1007/s13201-015-0360-5

[55] Mohebbi A, AbolghasemiMahani A, Izadi A (2019) Ion exchange resin technology in recovery of precious and noble metals. Appl Ion Exch Mater Chem Food Ind 9:193-258. h ttps://doi.org/10.1007/978-3-030-06085-5_9

[56] Salter RS, Wyslouzil DM, McDonald GW (eds) (1987) Proceedings of the international symposium of gold metallurgy. Pergamon Press, Canada

[57] Dada OA, Adekola FA, Odebunmi EO (2015) Kinetics and equilibrium models for sorption of $\mathrm{Cu}(\mathrm{II})$ onto a novel manganese nano-adsorbent. J Dispers Sci Technol 37:119-133. h ttps://doi.org/10.1080/01932691.2015.1034361

[58] Faghihian H, Nourmoradi H, Shokouh M (2014) Removal of copper (II) and nickel (II) from aqueous media using silica aerogel modified with amino propyl triethoxysilane as an adsorbent: equilibrium, kinetic, and isotherms study. Desalin
Water Treat 54:305-313. https://doi.org/10.1080/19443994. 2013.785367

[59] Samadi N, Ansari R, Khodavirdilo B (2017) Removal of Copper ions from aqueous solutions using polymer derivations of poly (styrene-alt-maleic anhydride). Egypt J Pet 26:375-389. https://doi.org/10.1016/j.ejpe.2016.05.010

[60] Cho DW, Jeon BH, Chon ChM, Kim Y, Schwartz FW, Lee ES, Song H (2012) A novel chitosan/clay/magnetite composite for adsorption of $\mathrm{Cu}(\mathrm{II})$ and $\mathrm{As}(\mathrm{V})$. Chem Eng $\mathrm{J}$ 200-202:654-662. https://doi.org/10.1016/j.cej.2012.06.126

[61] Wan Ngah WS, Teong LC, Toh RH, Hanafiah MAKM (2013) Comparative study on adsorption and desorption of $\mathrm{Cu}$ (II) ions by three types of chitosan-zeolite composites. Chem Eng J 223:231-238. https://doi.org/10.1016/j.cej.201 3.02 .090

[62] Sofińska-Chmiel W, Kołodyńska D (2018) Application of ion exchangers for the purification of galvanic wastewater from heavy metals. Sep Sci Technol 53:1097-1106. https://d oi.org/10.1080/01496395.2017.1330350

[63] Yahorava V, Kotze M, Auerswald D (2013) Evaluation of different adsorbents for copper removal from cobalt electrolyte. In: The Southern African Institute of Mining and Metallurgy Base Metals Conference 2013, pp 283-297

[64] Da'na E, Sayari A (2013) Modeling adsorption of copper on amine-functionalized SBA-15: predicting breakthrough curves. J Environ Eng 139(1):95-103. https://doi.org/10.10 61/(ASCE)EE.1943-7870.0000602

[65] Marsh H, Rodriguez F (2006) Activated carbon. Elsevier, Edinburgh

[66] Liu M, Deng Y, Zhan H, Zhang X (2002) Adsorption and desorption of copper(II) from solutions on new spherical cellulose adsorbent. J Appl Polym Sci 84:478-485. https://d oi.org/10.1002/app.10114

Publisher's Note Springer Nature remains neutral with regard to jurisdictional claims in published maps and institutional affiliations. 